\title{
Time-independent and time-dependent rheological 2 characterization of vegetable-based infant purees
}

\section{Dolores Alvarez*, Wenceslao Canet}

Department of Characterization, Quality and Safety, Institute of Food Science, Technology and Nutrition (ICTAN-CSIC), José Antonio Novais 10, 28040 Madrid, Spain

Running title

Rheology of vegetable-based infant purees

* Corresponding author. Tel.: +34 915492300; fax: +34 915493627.

58 E-mail address: mayoyes@ictan.csic.es (M.D. Alvarez). 


\section{ABSTRACT}

61 Flow behavior of vegetable-based infant purees was analyzed at different temperatures $\left(5-65{ }^{\circ} \mathrm{C}\right)$ giving 62 particular attention to their time-dependent properties in a shear rate range $\left(5-200 \mathrm{~s}^{-1}\right)$. Power law model 63 parameters describing flow behavior of samples depended on kind of infant puree, its water content and 64 measurement temperature. Arrhenius model was used to explain temperature effect on apparent viscosity at $50 \mathrm{~s}^{-}$

$65{ }^{1}$. Infant purees exhibited thixotropic behavior for all temperatures tested. For the same temperature, differences 66 in hysteresis loop magnitudes were observed among purees, being more noticeable at lower temperatures. Two 67 models were used to describe the time-dependent behavior, namely Weltman model, and second-order structural 68 kinetic model. For all infant purees, the initial shear stress and the extent of thixotropy increased and decreased 69 significantly with increases in shear rate and temperature. The breakdown rate of puree associations also 70 accelerated at higher shear rates, but no trend was observed with temperature.

71 Keywords: Flow behavior; flow time dependence; vegetable puree; baby foods; thixotropy; microstructure 72 


\section{Introduction}

74

Traditionally, infants have been supplemented by ready-to-eat formulated foods, commonly known as weaning foods (Ahmed and Ramaswamy, 2006a). Numerous weaning food preparations are marketed to satisfy different age groups and nutritional needs, and the majority of these foods are semisolid in nature making them easy to handle and feed to infants (Ahmed and Ramaswamy, 2006b). At present, Spanish formulations manufactured by a prominent and well-recognized manufacturer of baby foods in Europe contain different ingredients, and commonly include corn starch, olive oil and salt appropriately mixed with different vegetables and meat products (ranging between $11-12 \% \mathrm{w} / \mathrm{w}$ ).

Strained purees are obtained by processes that include both heat treatment and tissue destructuration and have been described as suspensions of soft particles in a viscous serum or gel (Choi and Yoo, 2004; ColinHenrion et al., 2007). Some foods especially starches and proteins undergo changes/modifications during processing resulting in a viscous dispersion, forming solutions or gels depending on temperature and concentration (Ahmed and Ramaswamy, 2006b). Generally, fluids with suspended particles have a certain shearsensitive structure, and most vegetable purees that are used as intermediate products are expected to undergo further low (mixing operations) to high (pumping) shear stresses (Van Hacke et al., 2012). It is therefore essential to understand their behavior in such conditions for process engineering calculations as well as for product development and quality control.

Formulation of a food product specifies the molecules that go into it, and the processing of these molecules leads to the formation of structures. Ingredients are themselves an assembly of molecules with associated structures (and textures) which can be modified, if these ingredients are combined with others and/or further processing is employed (Borwankar, 1992). Rheological studies contribute to our knowledge of the molecular structure or distribution of the molecular components of foods, as well as enabling us to predict the structural changes of food during the manufacturing processes (Koocheki and Razavi, 2009). When a material is sheared at a constant shear rate, the viscosity of a thixotropic material will decrease over a period of time, implying a progressive breakdown of structure (Abu-Jdayil, 2003). In addition, the characterization of time-dependent rheological properties of food systems is important to establish relationships between structure and flow, and to correlate physical parameters with sensory evaluation (Figoni and Shoemaker, 1983). Most food products are of a complex rheological nature, and their viscosity does not depend only on shear rate but also on the times that shear is applied. 
Results of dynamic rheology and differential scanning calorimetry of vegetable puree-based baby foods were presented by Ahmed and Ramaswamy (2006a). In turn, steady shear viscometry, covering the shear rate range 0.1 to $100 \mathrm{~s}^{-1}$, generally indicated the presence of yield stress and gave a good fit of data to the HerschelBulkley model in sweet potato puree infant food (Ahmed and Ramaswamy, 2006b). However, little information is available on the applicability of time-dependent flow models to vegetable or fruit puree-based baby foods. The Weltman model was recommended for banana puree (Choi and Yoo, 2004), which was also better that the Hahn model in describing the thixotropic behavior of four different infant foods (vegetable, meat, fish and dessert with six fruits) (Alonso et al., 1995).

A growing concern for safer foods has led research into increased infant food formulation and process monitoring procedures (Ahmed and Ramaswamy, 2006b). The emphasis of the baby food industry has been mostly on the nutritional content of such foods, with various combinations to provide infants with adequate energy (Ahmed and Ramaswamy, 2007a). Improvements in weaning foods have been achieved by the incorporation of protein-rich components from meat and fish and by reducing, to some extent, the flatulence and nutritional stress factors of legumes. Currently, baby food manufacturers of the products characterized in this study recommend on their labels that protein intake in infants should be lower than in adults, and that an excess of proteins is entirely inadvisable.

Nevertheless, in spite of the fact that the composition of baby foods, along with all other foodstuffs, is being continually modified and adapted with the aim of producing healthier foods, there are no recent rheological 121 studies of current commercial vegetable and fruit puree-based baby foods. The flow characterization of baby 122 food is very important with respect to the eating characteristics of the product (Ahmed and Ramaswamy, 123 2007b).The puree should be thick enough to stay in the spoon, but not so thick as to make swallowing difficult 124 (Steffe and Ford, 1985). This fact becomes especially important because consumption of baby foods is directed 125 at a population who cannot express their opinion (Alonso et al., 1995), thus impeding the acceptance or rejection of the products on the part of the baby consumers.

127 The first objective of this study was to characterize the flow behavior of four current commercial samples of 128 Spanish vegetable-based infant purees (all of them formulated together with meat products) with particular 129 attention being given to their time-dependent properties under the effect of different shearing conditions (5, 25, 13050,100 and $\left.200 \mathrm{~s}^{-1}\right)$, as well as studying the effect of temperature $\left(5,20,35,50\right.$ and $\left.65^{\circ} \mathrm{C}\right)$ on their rheology. A 131 second objective was to evaluate to what extent the rheological flow properties in these systems are related to microstructural features. 


\section{Materials and methods} study.

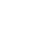

\subsection{Infant food samples}

Batches of four types of vegetable puree-based strained baby foods in $250 \mathrm{~g}$ retail jars were purchased from a local market. These baby foods were named by the manufacturer as: rice and chicken, selected vegetables with bass, vegetables and beef, and vegetables and chicken purees. The selected vegetable with bass puree is intended for an infant population aged eight months and over, whereas the other three purees are prepared for an infant populations of over six months. Each batch consisted of 50 jars of each vegetable puree, which were randomly purchased to obtain a more accurate representation of the product. After purchasing, the jars were stored in a dry, cool place with a minimal light environment and refrigerated immediately after opening. Each sample opened was discarded within $3 \mathrm{~h}$.

The total soluble solid (TSS) content $\mathrm{g} / 100 \mathrm{~g}(w / w)$ and $\mathrm{pH}$ of the samples were determined using a hand Atago (Itabashi-ku, Tokyo, Japan) dbx-30 refractometer and a Schott CG pH meter (Model 842; Schott-Geräte GmbH, Mainz, Germany), respectively. Expressible water for each sample was measured using centrifugal force according to Eliasson and Kim (1992). Dry matter content (\%) was determined by drying samples in a Philips microwave oven (model M-718, $700 \mathrm{~W}$ ) with output power at $70 \%$.

\subsection{Steady shear rheological measurements}

A Bohlin CVR 50 controlled stress rheometer (Bohlin Instruments Ltd., Cirencester, UK) was used to conduct steady shear experiments using a plate-plate sensor system with a $1 \mathrm{~mm}$ gap (PP40, $40 \mathrm{~mm}$ ) and a solvent trap to minimize moisture loss during tests. After loading the sample, there was a $5 \mathrm{~min}$ waiting period to allow the sample to recover and achieve temperature equilibrium. Temperature control was achieved with a Peltier Plate system $\left(-40\right.$ to $+180^{\circ} \mathrm{C}$; Bohlin Instruments). The sample temperature was ramped between 5 and $80{ }^{\circ} \mathrm{C}$ with incremental steps of $15{ }^{\circ} \mathrm{C}$. However, after data analysis, measurements at $80{ }^{\circ} \mathrm{C}$ were omitted as sample desiccation was clearly observed every so often at this temperature, under the test conditions used in this 
1. Flow curves with a controlled shear stress (CSS) in the range of 2.99-200 Pa, during a 10 min period at temperatures of $5,20,35,50$ and $65^{\circ} \mathrm{C}$. The experimental data were described by the power law model (Eq. 1) on the one hand and the Herschel-Bulkley model (Eq. 2) on the other hand (Rao, 1999) using Bohlin software CVO 120 (v. 06.40):

$$
\sigma=K \dot{\gamma}^{n}
$$

$$
\sigma=\sigma_{0}+K \dot{\gamma}^{n}
$$

where $\sigma$ is the shear stress $(\mathrm{Pa}), \dot{\gamma}$ is the shear rate $\left(\mathrm{s}^{-1}\right), K$ is the consistency index $\left(\mathrm{Pa} \mathrm{s}^{n}\right), n$ is the flow behavior index (dimensionless) and $\sigma_{0}$ is the yield stress $(\mathrm{Pa})$. The effect of temperature on apparent viscosity was described by the Arrhenius relationship:

$$
\eta_{\mathrm{a}}=\eta_{\infty A} \exp \left(E_{\mathrm{a}} / R T\right)
$$

2. Flow curves with a controlled shear rate (CSR) at temperatures of $5,20,35,50$ and $65^{\circ} \mathrm{C}$; the hysteresis loop was obtained by registering shear stress at shear rates from 0.1 to $100 \mathrm{~s}^{-1}$ in $5 \mathrm{~min}$ and down in $5 \mathrm{~min}$. Areas under the upstream data points $\left(A_{\text {up }}\right)$ and under the downstream data points $\left(A_{\text {down }}\right)$ as well as the hysteresis area $\left(A_{\mathrm{up}}-A_{\mathrm{down}}\right)$ were obtained using Bohlin software CVO 120 (v. 06.40). The percentage of relative hysteresis area (Dolz et al., 2000; Tárrega et al., 2004) was calculated by

$$
A_{\mathrm{r}}=\left(A_{\text {up }}-A_{\text {down }}\right) / A_{\text {up }} \times 100
$$

Both upstream and downstream data points were also fitted to the power law model (Eq. 1).

3. Curves showing the time-dependent behavior of shear stress in the time range of $0-40 \mathrm{~min}$ at $5,20,35,50$ and $65{ }^{\circ} \mathrm{C}$ with a constant shear rate of 5, 25, 50, 100 and $200 \mathrm{~s}^{-1}$. Experimental data were fitted to the Weltman model (Eq. 5) and to the structural kinetic model (SKM) of Nguyen et al. (1998) (Eq. 6), considering a second-order kinetics with $n=2$ (Abu-Jdayil, 2003; Tárrega et al., 2004; Van Hecke et al., 2012).

$$
\sigma=A+B \ln t
$$
thixotropic breakdown (Pa), and $t$ is the time of shearing (s). 


$$
\left[\frac{\left(\eta-\eta_{\mathrm{e}}\right)}{\left(\eta_{\mathrm{o}}-\eta_{\mathrm{e}}\right)}\right]^{1-n}=(n-1) k t+1
$$
viscosity as $t \rightarrow \infty$ (non-structured state), $k=k(\dot{\gamma})$ is the rate constant, and $n$ is the order of the structure breakdown reaction. Details and assumptions of this model can be found in Abu-Jdayil (2003).

Six and three replicates were respectively performed for flow behavior determination, (1), and time dependence characterization, $(2,3)$. The extent of fit for applied models was evaluated by determining the correlation coefficient $\left(R^{2}\right)$ between the experimental and predicted shear stress values.

Vegetable-based infant puree microstructure was examined by SEM using a Hitachi model S-2.100 microscope (Hitachi, Ltd., Tokyo, Japan). Samples were air-dried, then mounted and sputter-coated with Au (200 A approx.) in an SPI diode sputtering system metallizer. Photomicrographs were taken with a digital system Scanvision 1.2 of Röntgenanalysen-Technik ( $800 \times 1,200$ pixel, Rontec, GmbH, Berlin, Germany).

\subsection{Statistical analysis}

A two-way ANOVA was used to evaluate the effect of infant puree type, measurement temperature and interactions on rheological properties derived from time independent flow behavior and hysteresis loops. Moreover, to establish the effect of measurement temperature on each kind of infant puree separately, as well as the effect of the kind of infant puree at each measurement temperature, two one-factor ANOVA were performed.

211 A three-way ANOVA with interactions was applied to evaluate how infant puree type, measurement temperature and shear rate affect the parameters derived from the shear stress decay of the products. Additionally, to establish 213 the effect of measurement temperature at each shear rate in each vegetable-based infant puree, as well as the 214 effect of shear rate on each measurement temperature, two one-factor ANOVA were applied to the data.

215 Minimum significant differences were calculated by Fisher's least significant difference tests at significance level 0.05. Statistical analyses were carried out using a statistical SPSS 19.0 software package (SPSS, Inc., 
The TSS content of each of the different purees, namely rice and chicken, selected vegetable with bass, vegetables and beef, and vegetables and chicken purees was 11.2, 11.1, 9.2 and $9.5 \mathrm{~g} / 100 \mathrm{~g}(w / w)$, respectively. The respective values for $\mathrm{pH}$ were 4.62, 5.88, 5.60 and 5.84, for expressible water percentages $42.4 \%, 29.6 \%$, $37.4 \%$ and $18.7 \%$, and for dry matter content $82.8 \%, 84.1 \%, 85 \%$ and $84.8 \%$. Therefore, the rice and chicken puree had the highest TSS, moisture content and syneresis, but the lowest $\mathrm{pH}$. The company product specifications shown on labels are presented in Table 1 . The puree samples were rich in carbohydrates (especially the rice and chicken puree) with protein and fat contents within a narrow range of 3 to $3.4 \mathrm{~g} / 100 \mathrm{~g}$ and 2.1 to $2.5 \mathrm{~g} / 100 \mathrm{~g}$, respectively. The energy values ranged between 256 and $303 \mathrm{~kJ} / 100 \mathrm{~g}$. Protein and fat contents were higher and lower respectively than those reported by Ahmed and Ramaswamy (2006a, 2007a) for vegetable (pea, corn, and wax bean) and meat-based (chicken, lamb and beef) strained baby foods. This can be explained by the fact that all the vegetable puree-based baby foods presented in this study also contained meat products as mentioned above, although energy values of the samples were quite similar to those reported by the same authors for pea, corn and wax bean purees (Ahmed and Ramaswamy, 2006a).

Rheological properties of vegetable-based infant purees can be determined by the size of solid phase particles (Aguilar et al., 1991). It is thus clear from literature that by controlling particle size distribution it is possible to influence food processing optimization (Servais et al., 2002). The rheological properties of these infant foods are also influenced by their dry matter content, as well as by the current addition of olive oil fractions and thickeners. All the infant purees presented contain corn starch as thickener, although the amount incorporated is not specified on labels (Table 1). On the other hand, the rheological behavior of suspensions depends on measurement temperature, shear rate and time of shearing (Choi and Yoo, 2004). This study has been divided into time-independent flow behavior and time-dependent experiments.

\subsection{Time-independent flow behavior}

Examples of flow curves obtained with a controlled shear stress (CSS) for rice and chicken puree together with power law model fits obtained at different temperatures are presented in Fig. 1a, whilst Fig. 1b shows shear the classification of time-independent flow behavior of fluid foods shows that all the curves exhibited non- 
Newtonian shear-thinning behavior, which is a curvature downwards on the shear rate axis. Apparent viscosity 249 decreases markedly with increasing shear rate and with an increase in temperature (Fig. 1a). In Alonso et al. 250 (1995) and Ahmed and Ramaswamy (2006b, 2007a) other baby foods were also reported as having non251 Newtonian flow behavior. Rice and chicken puree exhibited the lowest shear stress values over all the shear rate range, whilst vegetable and chicken puree had the highest ones (Fig. 1b). The power law and Hershel-Bulkley models were used to describe flow curves of the vegetable-based infant purees. Parameters of the rheological models employed to describe the experimental data and the values of the apparent viscosity at $50 \mathrm{~s}^{-1}$, for six replicates, are summarized in Table 2. Based on the $R^{2}$ correlation coefficient values, the Hershel-Bulkley model exhibited a better fit than the power law model, though, some flow curves failed to adequately fit the former model. In addition, a negative yield stress was found in some cases. This model was found to be suitable for describing the flow of different meat-based infant foods after eliminating time dependency (Alonso et al., 1995), as well as the flow of fruit and sweet potato puree-based baby foods (Ahmed and Ramaswamy, 2006b, 2007b).

However, the yield stress value that is estimated from flow curves depends on the estimation equation (Canet et al., 2005; Witczak et al., 2011); therefore in this case yield stress should be interpreted as a model parameter rather than as the actual yield stress value which is a physical property of the fluid itself. On the other hand, the consistency coefficient had higher values for the Herschel-Bulkley model than for the power law model (Table 2), while flow behavior index values were lower for the Herschel-Bulkley model than for the power law model. This was probably due to that non-linear regression technique was used to estimate the parameters $\left(\sigma_{0}, K\right.$ and $\left.n\right)$ of the Herschel-Bulkley model, and the fact that the power law model disregards yield stress (Juszczak et al., 2004). Conversely, it is known that the consistency coefficient of a product should be higher when taking out the yield stress. Linear regression techniques also can be used for determination of the parameters of the Herschel-Bulkley model (when the magnitude of the yield stress is known from an independent experiment). Reasonably, the resulting straight line's intercept will be lower than that obtained from the power law model. Results confirm that estimated values of yield stress should be used only when

272 experimentally determined values are not available (Rao, 1999; Canet et al., 2005). Nevertheless, yield stress 273 values obtained in this study for rice and chicken puree are similar to data reported by such authors as Ahmed 274 and Ramaswamy (2006b) for sweet potato puree based baby food, but these authors recorded much lower values 275 for the Herschel-Bulkley consistency coefficient at the same temperatures. In other commercial vegetable infant 276 puree, Alonso et al. (1995) also obtained lower values for the Herschel-Bulkley consistency coefficient but 

drop in the value of the consistency coefficient and an increase in the flow behavior index value.

It should be noted that the SD for the consistency coefficient in the Hershel-Bulkley model was higher than that in the power law model for the following purees: selected vegetables with bass, vegetables and beef, and vegetables and chicken (Table 2). Nevertheless, although the power law model does not take into account yield stress, the model fitted the data quite well $\left(R^{2} \geq 0.99\right)$, and for rice and chicken puree, the degree of fit was higher than that obtained for the rest of the purees $\left(R^{2}=1.00\right)$. The inclusion of olive oil in the formulation of these baby foods in percentages ranging from 1.3 to 2 (Table 1) could account for the fact that the flow behavior of these products may be better described by the simpler power law model. The addition of extra virgin olive oil (either alone or blended) reduced apparent viscosity and pseudoplasticity of mashed potatoes, thereby producing softer systems, indicating that olive oil behaves as a soft filler (Alvarez et al., 2010). Therefore, this simple model was selected for the subsequent studies.

The results of the two one-way variance analysis showed that the kind of baby food and the measurement temperature, as well as the interaction between these two factors significantly affected the time-independent rheological parameters (Table 2). Consistency coefficient and yield stress values, together with apparent viscosity at $50 \mathrm{~s}^{-1}$ were the lowest for rice and chicken puree with the highest moisture content $(17.2 \%)$ and syneresis $(42.4 \%)$. These same parameters were highest for vegetable and chicken puree with lower water content $(15.2 \%)$ and the highest ability to immobilize water (syneresis $18.7 \%$ ). All vegetable-based infant puree samples had $n$ values of less than one which confirms that they exhibited non-Newtonian shear thinning flow behavior. Shear-thinning behavior is classically encountered in heterogeneous systems containing a dispersed phase. At rest, the particles are linked together by weak forces. When hydrodynamic forces during shear are sufficiently high, the interparticle linkages are broken, resulting in structural unit size reduction that, in turn, offers lower resistance to flow during shear (Van Hecke et al., 2012). The most pseudoplastic properties corresponded to vegetable and chicken puree with the lowest flow behavior indexes from both rheological models, which correspond with the highest shear stress values obtained for this puree (Fig. 1b). The highest $\sigma_{0}$ value for this baby food indicates that interparticular forces were greater than those of the other samples (Alonso 304 et al., 1995).

Certainly, the dry matter content of vegetable-based infant purees had an effect on their rheological properties: the lower it was, the lower the yield stress and consistency coefficients were. The opposite was true with respect to flow behavior; the lower the dry matter content, the higher the flow behavior index values. Rice 
and chicken puree with the highest carbohydrate content $(8.8 \mathrm{~g} / 100 \mathrm{~g})$ was clearly less viscous because of the plasticizing and diluting effect of the water (Sopade et al., 2002). However, since the vegetables and beef puree containing the lowest amount of water (15\%) had intermediate rheological properties, it would appear that these properties do not depend only on water content. Rheological property values may result from other factors such as content and the degree of protein hydration that are responsible for pseudo-gel structure formations in many foods, as well as carbohydrate content (Ahmed and Ramaswamy, 2006a, b; 2007a). Alonso et al. (1995)

314 suggested that flow resistance in meat and fish infant foods is mainly due to protein gel formation, produced by molecular interaction between protein molecules through hydrogen bonding, ionic bonding, disulfide bonding and hydrophobic association, although the authors did not give any data about product composition. In this study, rice and chicken and vegetables and chicken purees had the lowest and highest viscous properties respectively, in spite of both containing meat proteins from the same specie. Furthermore, the chicken content of rice and chicken puree (12\%) is higher than that for vegetables and chicken (11\%). In turn, vegetables and beef puree has the highest total protein content $(3.4 \mathrm{~g} / 100 \mathrm{~g})$, but also the smallest amount of carbohydrates (6.5 $\mathrm{g} / 100 \mathrm{~g}$ ) (Table 1). Certainly, the total protein content of vegetable-based infant foods would appear to be too low and similar to justify that protein content alone is responsible for the different rheological behavior observed between the samples. On the other hand, because pseudoplasticity is related to the average size of the particle of

324 the dispersed phase (Costell et al., 1982), it can be assumed that the rice and chicken puree had the smallest particles, while the vegetables and chicken puree had the largest ones, so much so that this fact could be appreciated with the naked eye, due to dissimilar finishing procedures. Moreover, an increase in particle content generally leads to higher viscous properties of pureed fruits and vegetables (Colin-Henrion et al., 2007).

Temperature significantly affects the viscosity of vegetable-based infant purees which decreases when temperature increases. In this study, both consistency coefficients, yield stress and apparent viscosity decreased when the temperature was increased (Table 2). In the case of rice and chicken puree, consistency coefficient values from the power law model fell from 13.52 at $5{ }^{\circ} \mathrm{C}$ to $5.04 \mathrm{~Pa} \mathrm{~s}^{\mathrm{n}}$ at $65{ }^{\circ} \mathrm{C}$, and apparent viscosity from 1.55 at $5{ }^{\circ} \mathrm{C}$ to $0.51 \mathrm{~Pa} \mathrm{~s}$ at $65^{\circ} \mathrm{C}$. A similar tendency was observed in the other baby foods. The effect of temperature on apparent viscosity is commonly described by the Arrhenius relationship (Eq. 3). The applicability of the

334 Arrhenius model to apparent viscosity at $50 \mathrm{~s}^{-1}$ versus temperature data on the vegetable-based infant purees is 335 shown in Fig. 2. Flow activation energy values $\left(E_{\mathrm{a}}\right)$ for rice and chicken, selected vegetables with bass, 336 vegetables and beef and vegetables and chicken purees, were 14.27, 10.64, 13.21 and $12.41 \mathrm{~kJ}^{\mathrm{mol}}{ }^{-1}$ respectively. It should be noted that vegetables and chicken puree had the worst fit to the Arrhenius model. Flow 
activation energy is a measure of changes in viscosity with increasing temperature and for Newtonian fluids ranges from $14.4 \mathrm{~kJ} \mathrm{~mol}^{-1}$ for water to more than $60 \mathrm{~kJ} \mathrm{~mol}^{-1}$ for sugar solutions and concentrated juices. Non-

340 Newtonian fluids, including purees, have much lower flow activation energy values (Krokida et al., 2001).

341 Consequently, rice and chicken puree was the most sensitive to temperature changes. The differences in $E_{\mathrm{a}}$ 342 values between samples are the result of many factors connected with sample composition. The change in 343 viscosity with unit temperature, i.e. per ${ }^{\circ} \mathrm{C}$ gave values between 0.79 and $2 \%$ for vegetable-based infant purees.

344 Roopa and Bhattacharya (2009) obtained values of this parameter ranging between 1.5 and $2.2 \%$ for aqueous 345 alginate dispersions. The apparent viscosity value of rice and chicken puree with the highest $E_{\mathrm{a}}$ value decreased 346 over 3-fold as temperature increased, while the apparent viscosity value of selected vegetables with bass, with 347 the lowest $E_{\mathrm{a}}$ value, decreased over 2.3-fold as temperature increased. The higher sensitivity of rice and chicken 348 puree could be ascribed to their higher water content, as well as to additional gelatinization of rice starch present 349 in this product. The lower $E_{\mathrm{a}}$ values of selected vegetables with bass puree could be due to the presence of more 350 fiber (1.5\%) binding water (Table 1). Changes in viscosity with unit temperature also increased with temperature 351 for all the infant foods (Table 2), which means that binding of ingredients with water decreases at elevated 352 temperatures.

\subsection{Time-dependent flow behavior}

Two methods were employed: hysteresis loop and shear stress decay. As an example, Fig. 3 shows flow curves obtained with a controlled shear rate $(\mathrm{CSR})$ at different temperatures $\left(5-65^{\circ} \mathrm{C}\right)$ for selected vegetables with bass and vegetables and chicken purees. The presence of a hysteresis area between the curves representing shear stress versus shear rate data for increasing and decreasing shear rates indicates that the flow of the samples was time-dependent (Tárrega et al., 2004). Therefore, the presence of hysteresis loops in Fig. 3 indicates thixotropic behavior of vegetable-based infant purees. Thus, the loop area designates the energy required to break down the structure that is not recovered during the experimentation period (Roopa and Bhattacharya, 2009), and depended on the kind of infant puree and measurement temperature.

364 The hysteresis loop areas for all the baby food purees under investigation at different temperatures are shown in Table 3. The two-way analysis of variance showed that the kind of puree and the temperature, as well 366 as their interaction significantly affected the hysteresis loop area, which was larger in vegetables and chicken 367 puree and smaller, in rice and chicken puree, implying more and less damage to the structures respectively. For 
the same temperature, differences in the form (Fig. 3) and magnitude of the hysteresis loop (Table 3) were observed among vegetable-based infant purees, these differences being more noticeable at $5{ }^{\circ} \mathrm{C}$. However, the significance of the interaction when considering the kind of puree sample and temperature as factors, and with the corresponding $F$ value $\left(F_{\text {int }}\right)$ being $94.76(p=0.000)$, indicated that the effect of temperature on this area was different depending on the type of infant puree. As expected, the loop area was significantly smaller at the higher temperatures for all the samples. As a result, the hysteresis loop area became smaller as the temperature increased from 5 to $65{ }^{\circ} \mathrm{C}$ for each infant puree. This probably indicates that the temperature effect on molecular structure damages the puree suspension. However, while the areas obtained at $65{ }^{\circ} \mathrm{C}$ were less than half the values at $5{ }^{\circ} \mathrm{C}$ for rice and chicken puree, these areas at $65{ }^{\circ} \mathrm{C}$ were less than a quarter of the values at $5{ }^{\circ} \mathrm{C}$ for the rest of the vegetables-based infant purees (Table 3). Apparently, these results disagree with the timeindependent flow activation energy values obtained for the different samples, which indicated that rice and chicken puree is more affected by temperature variations. Moreover, at $65{ }^{\circ} \mathrm{C}$, there were no significant differences between the hysteresis area values corresponding to rice and chicken puree and selected vegetables with bass. This phenomenon results from the fact that increasing temperature reduces thixotropy, and therefore the differences between samples become less significant when temperature increases. However, comparison of straight loop areas between different viscous systems may not render valid conclusions on the extension of timedependent structural breakdown (Tárrega et al., 2004). In our study, rice and chicken and vegetables and chicken purees showed not only the smallest and largest loop areas respectively, but also in the same order the lowest and highest resistance to flow.

An alternative approach may be the use of the relative thixotropic area under the ascending curve, defined as 388 the ratio of the "absolute" hysteresis area, which provides a more accurate study of the rate of internal structural 389 breakdown when comparing systems with different viscosities (Dolz et al., 2000). Considering the relative 390 thixotropic areas, a significant kind of baby food-temperature interaction $\left(F_{\text {int }}=6.69, p=0.000\right)$ was also found. 391 At the higher temperature $\left(65^{\circ} \mathrm{C}\right)$, for selected vegetables with bass, vegetables and beef and vegetables and 392 chicken purees, the relative areas were smaller but the decrease with respect to the values at $5{ }^{\circ} \mathrm{C}$ was lower than 393 that for the directly registered loop areas (Table 3). Conversely, for rice and chicken puree, the relative 394 thixotropic areas increased as the temperature increased. This increase indicates that in rice and chicken puree 395 the areas under the upstream data points decrease with temperature more significantly than their corresponding 396 hysteresis loops, thus supporting the results obtained for time-independent flow behavior. Furthermore, the 397 differences between samples were not the same when the relative areas were compared. Assuming that a 
hysteresis loop area is an index of the energy needed to destroy the structure responsible for flow time dependence, the experimental data showed that at 5,20 and $35{ }^{\circ} \mathrm{C}$ vegetables and chicken puree was the one needing the highest energy to break down such structure, while if the relative areas are considered the highest energy values at the same temperatures were shown by vegetables and beef puree.

The power law model was also used to describe the shear stress and shear rate data obtained at the CSR mode. The model exhibited a better fit when the descending curves were considered. Table 3 shows the fitting parameters of the power law model for the experimental data of vegetable-based infant purees at the different temperatures measured in the backward direction. The fitting of the experimental data was satisfactory with $R^{2} \geq$ 0.99 for all samples. Therefore, the application of the CSR mode considering the downward curves leads to better fits of the experimental data to the power law model than the CSS mode considering the ascending ones (Table 2). As expected, the consistency coefficients had lower values for the down curves in CSR mode (Table 3) than for the up ones using the CSS approach, while the values of the flow behavior index were greater for the downstream data points. In each puree type, consistency coefficient, $K$, significantly decreased with temperature. Unlike consistency coefficient, $n$ increased significantly with increasing temperature, the only exception being the vegetables and beef puree.

Time-dependent flow properties of vegetables-based infant purees were also measured by shearing the 414 samples at constant shear rates of 5, 25, 50, 100 and $200 \mathrm{~s}^{-1}$ over a temperature range of 5-65 ${ }^{\circ} \mathrm{C}$. The rate and 415 extent of shear stress decay varied among purees, temperatures and shear rates (Fig. 4). The observed time416 dependent flow behavior of vegetable-based infant purees was modeled using both an empirical equation-the 417 Weltman model (1943)-and the modified structural kinetics approach proposed by Nguyen et al. (1998). 418 Decreases in shear stress were more pronounced for higher-shear rates (Fig. 4a) and lower temperatures (Fig. 419 4b). A similar effect was reported for stirred yoghurt by Ramaswamy and Basak (1991) and O'Donnell and 420 Butler (2002) and for buttermilk by Butler and McNulty (1995). Their results showed that after $60 \mathrm{~min}$ of shearing at various constant shear rates, yoghurt and buttermilk continued to show structural decay. Weltman model regression parameters $A$ and $B$ are presented to compare the stress decay behavior of the 424 vegetable-based infant foods (Tables 4-7). The three-way analysis of variance showed that the kind of baby food, measurement temperature and shear rate significantly affected the $A$ and $B$ values, although the three binary interactions between factors also had a significant effect on both parameters. In most cases the experimental data 
measured at $5 \mathrm{~s}^{-1}\left(R^{2} \leq 0.90\right)$, and sometimes even at $25 \mathrm{~s}^{-1}$ as in the case of rice and chicken puree at 20 and 50

${ }^{\circ} \mathrm{C}$ (Table 4). This result is ascribed to a tiny build-up at low shear rates. Also, stress decay in selected vegetables with bass puree fitted rather poorly to the Weltman model at $65{ }^{\circ} \mathrm{C}$ (Table 5). This fact can be explained as a result of increased intermolecular interaction because of desiccation occurring towards the end of the $40 \mathrm{~min}$ shearing period at high temperature, as explained below.

In all the vegetables-based infant purees, parameter $A$ representing the shear stress needed for the structure 434 to start degrading, increased significantly as shear rate increased but decreased significantly as temperature increased. Similar results were reported by Choi and Yoo (2004) for banana baby food. In turn, parameter $B$ indicating the quantity of structure degraded during shearing (time coefficient of thixotropic breakdown) also increased as shear rate increased, except for vegetables and chicken puree at 5 and $50{ }^{\circ} \mathrm{C}$ at intermediate shear rates (Table 7). A negative value of $B$ measures how fast the shear stress drops from the initial value to the final equilibrium (steady-state) value (Koocheki and Razavi, 2009). Analogously, $B$ parameter values decreased when the measurement temperature increased, but again with the exception of the vegetables and chicken puree at the higher temperatures over the shear rate range of 50-200 s-1. Therefore, baby foods became somewhat less thixotropic at higher temperatures. Rice and chicken and vegetables and chicken purees showed the lowest and highest initial stress values at all the temperatures (Tables 4, 7), which were less than one-third at $65{ }^{\circ} \mathrm{C}$ than at 5 ${ }^{\circ} \mathrm{C}$. It is interesting to note that the $A$ and $B$ values were higher for selected vegetables with bass puree (Table 5) than for vegetables and beef (Table 6). Additionally, the $B$ value was higher for vegetables and chicken puree than for the rest of the baby foods at all temperatures, indicating its higher rate of structural breakdown by shearing and degree of thixotropy. According to Aguilar et al. (1991), Weltman model parameter values depend on the size distribution of solid particles suspended in the continuous phase.

Characteristically, since Weltman parameters represent different measures of shear stress, one would expect 450 to find a logarithmic relationship behavior between them and the shear rate (Ramaswamy and Basak, 1991). In 451 the present study, with only five shear rates employed for testing in the range of 5 to $200 \mathrm{~s}^{-1}$, exponential power 452 law models were found to describe the dependence of $A$ and $B$ on shear rate for rice and chicken puree, all 453 yielding high $R^{2}$ (Table 4). In the case of selected vegetables with bass and vegetables and beef purees (Tables 5 454 and 6 respectively), power law models were also the most adequate to characterize variations in $A$ as a function of $\dot{\gamma}$. However, logarithmic models were certainly found to describe better the dependence of $B$ on shear rate at some of the temperatures used. In the case of vegetables and chicken puree (Table 7), both logarithmic and 

logarithmic model described the dependence of $B$ on shear rate only at $35^{\circ} \mathrm{C}$ (Table 7).

In order to use the Arrhenius approach to describe the effect of temperature on the flow behavior of vegetable-based infant purees, apparent viscosities were evaluated, in this case, as $A / \dot{\gamma}$ ratios for the different shear rates, and regressed against the reciprocal absolute temperature. The activation energy $\left(E_{\mathrm{a}}\right)$ values show the temperature sensitivity of the inherent sample viscosity, and since $A$ values are estimates of shear stress prior to structure decay, they can be expected to match the $E_{\mathrm{a}}$ of flow (Ramaswamy and Basak, 1991). The associated $E_{\mathrm{a}}$ values of stress/viscosity decay are also summarized in Tables 4-7, and for all the infant purees these values were slightly higher that the $E_{\mathrm{a}}$ values reported above for the same products while obtaining shear stress-shear rate data under upward ramp shearing sequences (CSS mode). Fits of $A / \dot{\gamma}$ ratios to the Arrhenius model had lower $R^{2}$ values and were more dependent on shear rate in the case of vegetables and beef and vegetables and chicken purees (Tables 6,7).

The structural kinetics model postulates that the change in time-dependent flow properties is associated with shear-induced breakdown of the internal fluid structure and that the rate of this breakdown during shear depends on the kinetics of the structured state $\rightarrow$ non-structured state process (Abu-Jdayil, 2003; Tárrega et al., 2004). The rate constant, $k$ can be considered as a measure of the rate of structure breakdown, i.e. the degree of 474 thixotropy. On the other hand, the ratio of initial to equilibrium viscosity, $\eta_{0} / \eta_{\mathrm{e}}$, can be considered as a relative measurement of the amount of structure breakdown, or in other words as a relative measure of the extent of thixotropy (Abu-Jdayil, 2004). Initial viscosity $(t=4 \mathrm{~s}), \eta_{0}$, was obtained from the viscosity versus time data. As an example, Fig. 5 shows the effect of temperature on the thixotropic behavior of selected vegetables with bass 478 and vegetables and chicken purees at different shear rates. When a material is sheared at a constant shear rate, 479 the viscosity of a thixotropic material will decrease over a period of time, implying a progressive breakdown of 480 structure (Abu-Jdayil, 2003). According to Van Hecke et al., (2012) as the particles in carrot puree should be 481 considered as non-deformable owing to their cellulose content and high pulp volume fraction, the observed 482 thixotropic effect could be attributed to large particle size distribution. Smaller particles could act as lubricant for 483 the flow of the larger particles (Servais et al., 2002), thereby reducing the viscosity as the shear continues. 484 Apparent viscosity decreased significantly with time at all shearing levels and for all temperatures, particularly 485 in the initial stages of shear (Fig. 5). This implies that the configuration of polysaccharides and proteins in the 
towards a plateau, especially at higher temperatures. Analogously, viscosity tends to decay towards an equilibrium viscosity more rapidly at high shear rates, which is lower than that at low shear rates. Butler (2002) whereby the latter portions of the viscosity curves were fitted to an exponential decay curve of the form:

$$
\eta=\eta_{\mathrm{e}}+\mathrm{ae}^{-b t}
$$

where $\eta_{\mathrm{e}}$ was determined by choosing a trial value of $\eta_{\mathrm{e}}$ and calculating the line of best fit between $\log \left(\eta-\eta_{\mathrm{e}}\right)$ and $t$. The value of $\eta_{\mathrm{e}}$ that gave the best correlation was selected. For the shear rate range investigated, the $R^{2}$ values were all greater than 0.99 . In this study, the time at which the first viscosity measurement was taken $(t=4$ s) was considered to be zero time $\left(t_{0}\right)$. Analogously, $k$ values were determined using the first $25 \mathrm{~min}$ of data. In practice, this time period covers most flow situations encountered in the food industry (Butler and McNulty, 1995). Subsequently, to determine the applicability of the second-order SKM to the viscosity data of the vegetable-based baby foods, $\left[\left(\eta_{0}-\eta_{\mathrm{e}}\right) /\left(\eta-\eta_{\mathrm{e}}\right)\right]-1$ was plotted vs. time for each puree, shear rate and temperature. Some examples are shown in Fig. 6. The closeness of the linear fit validates the assumption of the second-order rate equation given by Eq. (6), at least during the first 25 min of shearing time. In this plot (Fig. 6), $k$ values are the slopes of the lines. Note that with large time values, a variation between the experimental results and the straight line approximation is to be expected as $\eta$ approaches $\eta_{\mathrm{e}}$ when $t \rightarrow \infty$ (Butler and McNulty, 1995; Van Hecke et al., 2012).

For the different vegetables-based infant purees, the values of $k$ and $\eta_{0} / \eta_{\mathrm{e}}$ as a function of the applied shear rate and the temperature are reported in Tables 4-7. Both rate constant $(k)$ and structural breakdown $\left(\eta_{0} / \eta_{\mathrm{e}}\right)$ were significantly $(P<0.05)$ affected by all the main factors (kind of puree, temperature and shear rate) and all the interactions of these factors. For rice and chicken infant puree $k$ increased significantly as shear rate increased at all the temperatures investigated (Table 4). This means that the breakdown rate of the structure subjected to external shear stress increased with increasing applied shear stress, and exponential power law models were also found to describe this dependence of $k$ on shear rate at each temperature studied. The effect of shear rate on $k$ values was the same for the rest of the baby foods studied, increasing significantly and exponentially with shear rate at temperatures ranging between 5 and $50{ }^{\circ} \mathrm{C}$ (Tables 5-7). Previous studies have also shown that for stirred 514 yogurt, $k$ could be related to shear rate using power law models (O'Donnell and Butler, 2002). In turn, the extent 515 of hysteresis increased significantly as shear rate increased in the temperature range of 5 to $50{ }^{\circ} \mathrm{C}$ for rice and 
also found that $\eta_{0} / \eta_{\mathrm{e}}$ decreased with increasing shear rate. For selected vegetables with bass and vegetables and beef purees, the value of $\eta_{0} / \eta_{\mathrm{e}}$ also increased significantly with shear rate in the same range of 5 to $50{ }^{\circ} \mathrm{C}$ (Tables 5 , 6). Finally, for vegetables and chicken puree, $\eta_{0} / \eta_{\mathrm{e}}$ again tended to increase with shear rate, but in this case the highest values did not always correspond with the highest shear rate.

It should be stated that at $65{ }^{\circ} \mathrm{C}$, for selected vegetables with bass, vegetables and beef, and vegetables and chicken purees, the shear stress decay data could not be fitted to the second-order SKM for most shear rates as viscosity increased towards the end of the 40 min shearing period. This fact is ascribed to increased extent of structuring due to water loss suffered by the samples under the experimental conditions used in this study, which impeded the estimation of the value of $\eta_{\mathrm{e}}$ in these cases. However, this effect was not detected during shearing, in rice and chicken puree, probably due to the fact that this product has higher moisture content. In contrast, meat protein denaturation (Ahmed and Ramaswamy, 2007a) and starch gelatinization (Ahmed and Ramaswamy, 2006a, b) occurring in the range of 65 to $80{ }^{\circ} \mathrm{C}$ were found to be the primary factors responsible for the unexpected rheological behavior of different baby foods in this temperature zone, which was confirmed by thermal transition behavior. At each shear rate and infant puree studied, both the decay rate constant $(k)$ and the extent of thixotropy did not have any trend with temperature between 5 and $65{ }^{\circ} \mathrm{C}$ (Tables 4-7). Nguyen et al. (1998) reported that $k$ values for starch pastes increased or decreased with temperature depending on the type of starch and on the applied shear rate. For the products analyzed in this paper, these characteristics will depend not only on the starch content of the samples but also on the elaboration process conditions, mainly on the severity of the cooking process and the degree of grinding.

Examination of the suitability of the time-dependent rheological models, as assessed by the correlation coefficient (Tables 4-7), indicated that except in the above-mentioned cases, both were suitable for characterizing the time-dependent rheological behavior of the vegetable-based infant purees. In all the baby foods studied, both Weltman parameters $A$ and $B$, showed a clear tendency to increase and decrease in line with shear rate and temperature respectively. Therefore, the Weltman model could be considered better than the second-order SKM for characterizing these products under the conditions studied, besides being less tedious.

\subsection{Microstructure examination}

Fig. 7 shows the morphological differences between the infant purees studied. The microstructure of the baby foods consists of a network made up of mainly different starch type components released from the granules 
and protein, together with fat and fiber from different sources. In rice and chicken puree (Fig. 7a), it would appear that finer grinding produced a more homogeneous, regular microstructure, with amylose and amylopectin released from gelatinized starch granules forming a reticular network, closely resembling an emulsion and with less appreciable protein structures. Although starch granule integrity is expected to be lost during the manufacturing process (cooking), some gelatinized starch granules which were not broken down are still recognizable. In this study, the finer the particle sizes were the lower the flow rheological properties, as observed in the case of rice and chicken puree.

The presence of meat protein structures was more apparent in micrographs corresponding to the other three vegetable-based infant foods studied (Figs. 7b-d) as they had all been more coarsely ground, especially in the case of vegetables and chicken puree. In this product the protein network structure was more continuous and dense (Fig. 7d), and much less dispersed in the starch component matrix. This transition to a more discontinuous phase containing structures which were coarser, more irregular, compact and aggregated is reflected by a very significant increase in flow rheological properties in comparison to the rest of the baby food systems. The microstructures of selected vegetables with bass (Fig. 7b) and vegetables and beef (Fig. 7c) purees were certainly intermediate, between those of the rice and chicken and the vegetables and chicken purees, a fact that was also reflected in intermediate rheological properties. In selected vegetables with bass puree, the higher fiber content resulted in a more compact microstructure with a more porous appearance. Some oil droplets can be observed immersed in the network. Bass protein structures remained separate from and hence not integrated in the starch matrix, though in some cases they had occupied empty cavities (Fig. 7b). In vegetables and beef puree, meat protein appeared to be integrated in the amylose and amylopectin matrix, exhibiting a kind of mesh with connections between structural elements. Some published reports have indicated that during heating, starch exhibits little affinity for myofibrillar proteins, so that instead of interacting with the protein matrix, it acts as passive filler (Fernández et al., 1998). This fact could explain the lower time dependent rheological properties obtained for this puree in comparison to the puree containing fish. On the other hand, all the purees contain potato and carrot. According to Bengtsson and Tornberg (2011), carrot and potato pulp suspensions consist of large cell clusters and aggregates, respectively, which are degraded into smaller cell clusters when homogenized.

573 However, a high content of insoluble pectin in carrot and potato pulp keeps the cells closely associated with each

574 other. Both vegetables and beef and vegetables and chicken purees also contain tomato, but the tomato 575 suspensions were found to consist of large, single cells and cell fragments which were easily degraded by 576 homogenization. 


\section{Conclusions}

578

579 It was found that vegetable-based infant purees exhibited shear thinning and thixotropic behavior for all temperatures tested $\left(5-65^{\circ} \mathrm{C}\right)$. Data of the baby foods studied fitted the power law model well, mainly in the case

581 of rice and chicken puree with its higher moisture content and degree of homogenization. In addition, in all the infant purees, the degree of fit was higher after partially eliminating flow time dependence. The hysteresis loop

583 area was larger in the vegetables and chicken puree but smaller in the rice and chicken puree, implying more and

584 less damage to the structures respectively. On the other hand, all the vegetable-based infant purees became less 585 thixotropic at higher temperatures. Both initial shear stress and the time coefficient of thixotropic breakdown 586 (parameters $A$ and $B$ in the Weltman model respectively) increased and decreased respectively at high shear rates

587 and temperatures. In other words, increasing the shear rate leads to an increase in the degree of thixotropy. In vegetables and chicken puree, higher values for $B$ indicated its higher rate of structural breakdown by shearing.

589 This fact is ascribed to the lower degree of homogenization observed in this baby food. The rate and extent of 590 viscosity decay were also higher at the higher shear rate, but the amount of structural breakdown of infant purees 591 showed no tendency to either increase or decrease with temperature. In view of the above results, the factors that could best explain the differences in the rheological and microstructural properties of vegetable-based infant

593 purees are: the degree of grinding undergone by each infant food, the meat or fish particle size and the degree of 594 homogenization of the product, as well as the origin of the various proteins (chicken, bass or beef). Results also 595 evidenced a strong dependence of infant puree viscosity on water content. 
598 The authors wish to thank the Spanish Ministry of Economy and Competitiveness for financial support 599 (AGL2011-28569), and P. Adeva and A. García of the Electron Miscroscopy Laboratory at the Spanish National 600 Metallurgical Research Center (CENIM-CSIC).

601 
Abu-Jdayil, B., 2003. Modelling the time-dependent rheological behaviour of semisolid foodstuffs. Journal of Food Engineering 57, 97-102.

Abu-Jdayil, B., 2004. Flow properties of sweetened sesame paste (halawa tehineh). European Food Research \& Technology 219, 265-272.

Aguilar, C., Rizvi, S.S.H., Ramirez, J.F., Inda, A., 1991. Rheological behavior of processed mustard. I. Effect of milling treatment. Journal of Texture Studies 22, 59-84.

610 Ahmed, J., Ramaswamy, H.S., 2006a. Viscoelastic and thermal characteristics of vegetable-puree based baby foods. Journal of Food Process Engineering 29, 219-233.

612 Ahmed, J., Ramaswamy, H.S., 2006b. Viscoelastic properties of sweet potato puree infant food. Journal of Food Engineering 74, 376-382.

614 Ahmed, J., Ramaswamy, H.S., 2007a. Dynamic rheology and thermal transitions in meat-based strained baby foods. Journal of Food Engineering 78, 1274-1284.

616 Ahmed, J., Ramaswamy, H.S., 2007b. Dynamic and steady shear rheology of fruit puree based baby foods. Journal of Food Science and Technology 44, 579-585.

618 Alonso, M.L., Larrodé, O., Zapico, J., 1995. Rheological behaviour of infant foods. Journal of Texture Studies 26, 193-202.

620 Alvarez, M.D., Fernández, C., Olivares, M.D., Canet, W., 2010. Rheological behaviour and functionality of inulin-extra virgin olive oil-based mashed potatoes. International Journal of Food Science and Technology $45,2108-2118$.

Bengtsson, H., Tornberg, E. 2011. Physicochemical characterization of fruit and vegetables fiber suspensions. I: effect of homogenization. Journal of Texture Studies 42, 268-280.

626 Butler, F., McNulty, P., 1995. Time dependent rheological characterisation of buttermilk at $5{ }^{\circ} \mathrm{C}$. Journal of Food Engineering 25, 569-580.

628 Canet, W., Alvarez, M.D., Fernández, C., Luna, P. 2005. Comparisons of methods for measuring yield stresses in potato puree: effect of temperature and freezing. Journal of Food Engineering 68, 143-153.

630 Choi, Y.H., Yoo, B., 2004. Characterization of time-dependent flow properties of food suspensions. International 631 Journal of Food Science and Technology 39, 801-805. 
Colin-Henrion, M., Cuvelier, G., Renard, C.M.G.C. 2007. Texture of pureed fruit and vegetable foods. Stewart Postharvest Review 5, 1-14.

634 Costell, E., Clemente, G., Durán, L., 1982. Reología físico-química del puré de albaricoque. II. Caracterización del flujo y relación entre los parámetros reológicos y las características químicas y físicas del producto. Revista de Agroquímica y Tecnología de Alimentos 22, 539-550.

Dolz, M., González, F., Delegido, J., Hernández, M.J., Pellicer, J., 2000. A time-dependent expresión for thixotropic areas. Application to aerosol 100 hydrogels. Journal of Pharmaceutical Sciences 89, 790-797.

Eliasson, A.C., Kim, H.R., 1992. Changes in rheological properties of hydroxypropyl potato starch pastes during freeze-thaw treatments I. A rheological approach for evaluation of freeze-thaw stability. Journal of Texture Studies 23, 279-295.

Fernández, P., Cofrades, S., Solas, M.T., Carballo, J., Jiménez Colmenero, F., 1998. High pressure-cooking of chicken meta batters with starch, egg white, and iota carrageenan. Journal of Food Science 63, 267-271.

Figoni, P.I., Shoemaker, C.F., 1983. Characterization of time dependent flow properties of mayonnaise under steady shear. Journal of Texture Studies 14, 431-442.

Koocheki, A., Razavi, S.M.A., 2009. Effect of concentration and temperature on flow properties of Alyssum homolocarpum seed gum solutions: assessment of time dependency and thixotropy. Food Biophysics 4, 353364.

Krokida, M.K., Maroulis, Z.B., Saravacos, G.D., 2001. Rheological properties of fluid fruit and vegetables puree products: compilation of literature data. International Journal of Food Properties 2, 179-200.

Juszczak, L., Witczak, M., Fortuna, T., Banyś, A., 2004. Rheological properties of commercial mustards. Journal of Food Engineering 63, 209-217.

Nguyen, Q.D., Jensen, C.T.B., Kristensen, P.G., 1998. Experimental and modelling studies of the flow properties of maize and waxy maize starch pastes. Chemical Engineering Journal 70, 165-171.

O’Donell, H.J., Butler, F., 2002. Time-dependent viscosity of stirred yogurt. Part I: Coutte flow. Journal of Food Engineering 51, 249-254.

Ramaswamy, H.S., Basak, S. 1991. Time dependent stress decay rheology of stirred yogurt. International Dairy Journal 1, 17-31.

Rao, M.A. (1999). Flow and functional models for rheological properties of fluid foods. In G. V. BarbosaGaithersburg, MD: Aspen Publishers Inc. 
Roopa, B.S., Bhattacharya, S., 2009. Characterisation and modelling of time-independent and time-dependent

663

664

665

666

667

668

669

670

671

672

673

674

675

676

677

678

680

679 Witczak, M., Juszczak, L., Galkowska, D., 2011. Non-Newtonian behaviour of heather honey. Journal of Food flow behaviour of sodium alginate dispersions. International Journal of Food Science and Technology 44, 2583-2589.

Servais, C., Jones, R., Roberts, I., 2002. The influence of particle size distribution on the processing of food. Journal of Food Engineering 51, 201-208.

Sopade, P.A., Halley, P.J., Bhandari, B., D’Arcy, B.R., Doebler, C., Caffin, N., 2002. Application of the Williams-Landel-Ferry model to the viscosity-temperature relationship of Australian honeys. Journal of Food Engineering 56, 67-75.

Sttefe, J.F., Ford, E.W., 1985. Rheological techniques to evaluate the shelf-stability of starch-thickened, strained apricots. Journal of Texture Studies 16, 179-192.

Tárrega, A., Durán, L., Costell, E., 2004. Flor behaviour of semi-solid dairy desserts. Effect of temperature. International Dairy Journal 14, 345-353.

Van Hecke, E., Nguyen, P.-U., Clausse, D., Lanoisellé, J.-L., 2012. Flow behaviour of carrot puree: modelling the influence of time, temperature and potato flakes addition. International Journal of Food Science and Technology 47, 177-185.

Weltman, R.N., 1943. Breakdown of thixotropic structure as a function of time. Journal of Applied Physics 14, $348-350$. 681 
684 Fig. 1. Flow curves with a controlled shear stress (CSS mode) of vegetable-based infant purees measured by 685 increasing shear rate (forward measurements). (a) Rice and chicken puree at different temperatures fitted to the 686 power law model; (b) Vegetable-based infant purees at $35^{\circ} \mathrm{C}$ fitted to the Herschel-Bulkley model.

687 Fig. 2. Plots of apparent viscosity (CSS mode) vs. temperature for vegetable-based infant purees.

688 Fig. 3. Flow curves with a controlled shear rate (CSR mode) measured by increasing (forward measurements)

689 and decreasing shear rate (backward measurements) at temperatures of 5, 20, 35, 50 and $65{ }^{\circ} \mathrm{C}$. (a) Selected 690 vegetables with bass puree; (b) Vegetables and chicken puree.

691 Fig. 4. Experimental and predicted shear stress values as a function of shearing time. (a) Rice and chicken puree

692 at $35{ }^{\circ} \mathrm{C}$ at different shear rates $\left(5-200 \mathrm{~s}^{-1}\right)$. (b) Vegetables and beef puree sheared at $100 \mathrm{~s}^{-1}$ at different 693 temperatures $\left(5-65^{\circ} \mathrm{C}\right)$.

694 Fig. 5. Experimental and predicted apparent viscosity values as a function of shearing time at different 695 temperatures $\left(5-65^{\circ} \mathrm{C}\right)$. (a) Selected vegetables with bass puree at a constant shear rate of $100 \mathrm{~s}^{-1}$; (b) Vegetables 696 and chicken puree at a constant shear rate of $25 \mathrm{~s}^{-1}$.

697 Fig. 6. Testing of the second-order structural kinetic model, Eq. (6), for some vegetable-based infant purees. (a)

698 Rice and chicken puree at $50{ }^{\circ} \mathrm{C}$ and different shear rates; (b) Vegetables and chicken puree at a constant shear 699 rate of $100 \mathrm{~s}^{-1}$ and different temperatures.

700 Fig. 7. Micrographs of vegetable-based infant purees. (a) Rice and chicken puree; (b) Selected vegetables with 701 bass puree; (c) Vegetables and beef puree; (d) Vegetables and chicken puree. 


\section{Table 1}

Composition and ingredient information of vegetable puree-based baby foods*

\begin{tabular}{|c|c|c|c|c|}
\hline \multirow[t]{2}{*}{ Composition } & \multicolumn{4}{|l|}{ Puree $(\mathrm{g} / 100 \mathrm{~g})$} \\
\hline & $\begin{array}{l}\text { Rice and } \\
\text { chicken }\end{array}$ & $\begin{array}{l}\text { Selected } \\
\text { vegetables with } \\
\text { bass }\end{array}$ & $\begin{array}{l}\text { Vegetables and } \\
\text { beef }\end{array}$ & $\begin{array}{l}\text { Vegetables and } \\
\text { chicken }\end{array}$ \\
\hline Protein & 3.3 & 3.0 & 3.4 & 3.1 \\
\hline Carbohydrate & 8.8 & 7.4 & 6.5 & 7.3 \\
\hline of which sugar & 2.4 & 2.5 & 1.2 & 1.0 \\
\hline Fat & 2.5 & 2.3 & 2.1 & 2.2 \\
\hline of which saturated & 0.5 & 0.3 & 1.0 & 0.4 \\
\hline Fiber & 0.6 & 1.5 & 1.3 & 1.2 \\
\hline Sodium & 0.042 & 0.066 & 0.055 & 0.065 \\
\hline Ingredients & $\begin{array}{l}\text { Cooking water, } \\
\text { reconstituted } \\
\text { skimmed milk } \\
\text { powder, potato, } \\
\text { chicken }(12 \%), \\
\text { carrot, rice }(4 \%) \text {, } \\
\text { corn starch, olive } \\
\text { oil }(1.5 \%), \text { lactose } \\
\text { and salt. }\end{array}$ & $\begin{array}{l}\text { Cooking water, } \\
\text { reconstituted } \\
\text { skimmed milk } \\
\text { powder, vegetables } \\
(58 \%) \text { (carrot, } \\
\text { potato, onion, peas, } \\
\text { green beans and } \\
\text { leek), bass }(12 \%) \\
\text { corn starch, olive oil } \\
(2 \%), \text { lactose and } \\
\text { salt. }\end{array}$ & $\begin{array}{l}\text { Cooking water, } \\
\text { potato, beef }(12 \%) \text {, } \\
\text { carrot, peas, tomato, } \\
\text { onion, green bean, } \\
\text { leek, corn starch, } \\
\text { olive oil }(1.3 \%) \text { and } \\
\text { salt. }\end{array}$ & $\begin{array}{l}\text { Cooking water, } \\
\text { potato, chicken } \\
(11 \%) \text {, carrot, peas, } \\
\text { tomato, onion, } \\
\text { green bean, leek, } \\
\text { corn starch, olive } \\
\text { oil }(1.3 \%) \text { and salt. }\end{array}$ \\
\hline
\end{tabular}

* Provided by the manufacturer. 
Table 2

Rheological parameters of power law and Herschel-Bulkley models describing flow curves of vegetable-based infant purees and apparent viscosity at $50 \mathrm{~s}^{-1}$

\begin{tabular}{|c|c|c|c|c|c|c|c|c|c|c|}
\hline \multirow{2}{*}{$\begin{array}{l}\text { Vegetable- } \\
\text { based infant } \\
\text { puree type }\end{array}$} & \multirow{2}{*}{$\begin{array}{l}\text { Temperature } \\
\left({ }^{\circ} \mathrm{C}\right)\end{array}$} & \multicolumn{3}{|l|}{ Power law model } & \multicolumn{4}{|c|}{ Herschel-Bulkley model } & \multirow{2}{*}{$\begin{array}{l}\eta_{\mathrm{a}} \text { at } 50 \mathrm{~s}^{-1} \\
(\mathrm{~Pa} \mathrm{~s})\end{array}$} & \multirow{2}{*}{$\begin{array}{l}\text { Change in } \\
\eta_{\mathrm{a}} \text { per }{ }^{\circ} \mathrm{C} \\
(\%)\end{array}$} \\
\hline & & $K\left(\mathrm{~Pa} \mathrm{~s}^{\mathrm{n}}\right)$ & $n$ & $R^{2}$ & $\sigma_{0}(\mathrm{~Pa})$ & $K\left(\mathrm{~Pa} \mathrm{~s}^{\mathrm{n}}\right)$ & $n$ & $R^{2}$ & & \\
\hline $\begin{array}{l}\text { Rice and } \\
\text { chicken }\end{array}$ & $\begin{array}{l}5 \\
20 \\
35 \\
50 \\
65 \\
\end{array}$ & $\begin{array}{l}13.52 \pm 0.64^{\mathrm{A}}{ }_{\mathrm{d}} \\
10.77 \pm 0.98^{\mathrm{B}}{ }_{\mathrm{d}} \\
7.71 \pm 0.06^{\mathrm{C}} \mathrm{d}^{\mathrm{d}} \\
5.93 \pm 0.05^{\mathrm{D}}{ }_{\mathrm{c}} \\
5.04 \pm 0.13^{\mathrm{D}}{ }_{\mathrm{d}}\end{array}$ & $\begin{array}{l}0.45 \pm 0.01^{\mathrm{A}, \mathrm{B}}{ }_{\mathrm{a}} \\
0.44 \pm 0.00^{\mathrm{B}}{ }_{\mathrm{a}} \\
0.44 \pm 0.00^{\mathrm{B}}{ }^{\mathrm{a}} \\
0.45 \pm 0.00^{\mathrm{A}}{ }^{\mathrm{a}} \\
0.41 \pm 0.00^{\mathrm{C}}{ }^{\mathrm{a}} \\
\end{array}$ & $\begin{array}{l}1.00 \\
1.00 \\
1.00 \\
1.00 \\
1.00 \\
\end{array}$ & $\begin{array}{l}2.83 \pm 0.54^{\mathrm{A}}{ }_{\mathrm{d}} \\
1.85 \pm 0.21^{\mathrm{B}}{ }^{\mathrm{c}} \\
1.64 \pm 0.40^{\mathrm{B}}{ }^{\mathrm{c}} \\
1.54 \pm 0.03^{\mathrm{B}}{ }^{\mathrm{c}} \\
0.24 \pm 0.11^{\mathrm{C}}{ }_{\mathrm{b}}\end{array}$ & $\begin{array}{l}16.85 \pm 0.96^{\mathrm{A}}{ }_{\mathrm{d}} \\
11.97 \pm 0.22^{\mathrm{B}}{ }_{\mathrm{d}} \\
9.25 \pm 0.48^{\mathrm{C}}{ }_{\mathrm{c}} \\
7.36 \pm 0.06^{\mathrm{D}}{ }_{\mathrm{c}} \\
4.71 \pm 0.09^{\mathrm{E}}{ }_{\mathrm{c}}\end{array}$ & $\begin{array}{l}0.40 \pm 0.01^{\mathrm{B}}{ }^{\mathrm{a}} \\
0.41 \pm 0.00^{\mathrm{B}} \mathrm{a}^{\mathrm{a}} \\
0.41 \pm 0.01^{\mathrm{B}}{ }^{\mathrm{a}} \\
0.41 \pm 0.01^{\mathrm{B}}{ }^{\mathrm{a}} \\
0.43 \pm 0.01^{\mathrm{A}}{ }_{\mathrm{a}}\end{array}$ & $\begin{array}{l}1.00 \\
1.00 \\
1.00 \\
1.00 \\
1.00\end{array}$ & $\begin{array}{l}1.55 \pm 0.03^{\mathrm{A}} \mathrm{d} \\
1.17 \pm 0.01^{\mathrm{B}}{ }^{\mathrm{d}} \\
0.89 \pm 0.01^{\mathrm{C}}{ }^{\mathrm{c}} \\
0.70 \pm 0.01^{\mathrm{D}}{ }^{\mathrm{c}} \\
0.51 \pm 0.01^{\mathrm{E}}{ }_{\mathrm{d}}\end{array}$ & $\begin{array}{l}1.64 \\
1.60 \\
1.42 \\
2.00\end{array}$ \\
\hline $\begin{array}{l}\text { Selected } \\
\text { vegetables } \\
\text { with bass }\end{array}$ & $\begin{array}{l}5 \\
20 \\
35 \\
50 \\
65\end{array}$ & $\begin{array}{l}29.91 \pm 0.46^{\mathrm{A}}{ }_{\mathrm{c}} \\
23.07 \pm 1.18^{\mathrm{B}}{ }^{\mathrm{c}} \\
18.64 \pm 0.52^{\mathrm{C}}{ }^{\mathrm{c}} \\
16.90 \pm 1.95^{\mathrm{C}^{\mathrm{C}}} \\
14.31 \pm 0.57^{\mathrm{D}} \mathrm{c}\end{array}$ & $\begin{array}{l}0.31 \pm 0.01^{\mathrm{A}-\mathrm{C}}{ }_{\mathrm{b}} \\
0.32 \pm 0.02^{\mathrm{A}, \mathrm{B}}{ }_{\mathrm{b}}^{\mathrm{B}} \\
0.36 \pm 0.02^{\mathrm{A}}{ }_{\mathrm{b}}^{\mathrm{b}} \\
0.29 \pm 0.04^{\mathrm{B},{ }^{\mathrm{C}}{ }_{\mathrm{b}}} \\
0.26 \pm 0.01^{\mathrm{C}}{ }_{\mathrm{c}}\end{array}$ & $\begin{array}{l}0.99 \\
0.99 \\
0.99 \\
1.00 \\
1.00\end{array}$ & $\begin{array}{l}8.55 \pm 0.08^{\mathrm{A}}{ }^{\mathrm{C}} \\
6.50 \pm 1.78^{\mathrm{A}, \mathrm{B}} \mathrm{b} \\
6.24 \pm 0.94^{\mathrm{B}}{ }_{\mathrm{b}} \\
3.24 \pm 0.22^{\mathrm{C}}{ }_{\mathrm{b}} \\
2.08 \pm 0.53^{\mathrm{C}}{ }_{\mathrm{a}}\end{array}$ & $\begin{array}{l}42.71 \pm 0.64^{\mathrm{A}}{ }^{\mathrm{c}} \\
32.44 \pm 1.25^{\mathrm{B}}{ }^{\mathrm{c}} \\
28.68 \pm 2.69^{\mathrm{B}}{ }^{\mathrm{b}} \\
22.82 \pm 2.56^{\mathrm{C}}{ }_{\mathrm{b}} \\
13.56 \pm 1.79^{\mathrm{D}}{ }_{\mathrm{b}}\end{array}$ & $\begin{array}{l}0.23 \pm 0.00^{\mathrm{C}}{ }_{\mathrm{b}} \\
0.25 \pm 0.00^{\mathrm{B}, \mathrm{C}_{\mathrm{b}}}{ }_{\mathrm{b}} \mathrm{b} \\
0.24 \pm 0.01^{\mathrm{B}, \mathrm{C}_{\mathrm{b}}} \\
0.26 \pm 0.01^{\mathrm{B}}{ }_{\mathrm{b}}^{\mathrm{b}} \\
0.32 \pm 0.01^{\mathrm{A}}{ }_{\mathrm{b}}\end{array}$ & $\begin{array}{l}1.00 \\
1.00 \\
1.00 \\
1.00 \\
1.00\end{array}$ & $\begin{array}{l}1.94 \pm 0.01^{\mathrm{A}}{ }^{\mathrm{c}} \\
1.57 \pm 0.02^{\mathrm{B}}{ }^{\mathrm{c}} \\
1.30 \pm 0.03^{\mathrm{C}} \mathrm{b}^{\mathrm{b}} \\
1.07 \pm 0.01^{\mathrm{D}} \mathrm{b}^{\mathrm{b}} \\
0.84 \pm 0.02^{\mathrm{E}}{ }_{\mathrm{c}}\end{array}$ & $\begin{array}{l}1.27 \\
1.15 \\
1.18 \\
1.43\end{array}$ \\
\hline $\begin{array}{l}\text { Vegetables } \\
\text { and beef }\end{array}$ & $\begin{array}{l}5 \\
20 \\
35 \\
50 \\
65\end{array}$ & $\begin{array}{l}36.01 \pm 0.81^{\mathrm{A}} \mathrm{b} \\
26.92 \pm 0.35^{\mathrm{B}}{ }^{\mathrm{b}} \\
22.44 \pm 0.13^{\mathrm{C}} \\
16.68 \pm 0.82^{\mathrm{D}}{ }^{\mathrm{b}} \\
12.80 \pm 0.43^{\mathrm{E}}\end{array}$ & $\begin{array}{l}0.30 \pm 0.01^{\mathrm{A}}{ }_{\mathrm{c}} \\
0.30 \pm 0.01^{\mathrm{A}}{ }_{\mathrm{b}} \\
0.27 \pm 0.00^{\mathrm{B}}{ }_{\mathrm{c}} \\
0.29 \pm 0.02^{\mathrm{A}}{ }_{\mathrm{b}} \\
0.29 \pm 0.01^{\mathrm{A},{ }_{\mathrm{B}}}{ }_{\mathrm{b}}\end{array}$ & $\begin{array}{l}0.99 \\
0.99 \\
0.99 \\
1.00 \\
1.00\end{array}$ & $\begin{array}{l}13.35 \pm 0.18^{\mathrm{A}}{ }_{\mathrm{b}} \\
9.77 \pm 0.16^{\mathrm{B}}{ }^{\mathrm{a}} \\
4.05 \pm 0.17^{\mathrm{C}^{2}} \\
3.03 \pm 1.02^{\mathrm{C}, \mathrm{D}} \\
2.37 \pm 0.08^{\mathrm{D}}{ }_{\mathrm{a}}\end{array}$ & $\begin{array}{l}54.84 \pm 0.93^{\mathrm{A}}{ }_{\mathrm{b}} \\
39.78 \pm 0.64^{\mathrm{B}}{ }^{\mathrm{b}} \\
26.94 \pm 0.25^{\mathrm{C}}{ }_{\mathrm{b}} \\
19.98 \pm 1.21^{\mathrm{D}}{ }^{\mathrm{b}} \\
18.49 \pm 2.43^{\mathrm{D}}{ }_{\mathrm{a}}\end{array}$ & $\begin{array}{l}0.21 \pm 0.00^{\mathrm{D}}{ }_{\mathrm{c}} \\
0.22 \pm 0.00^{\mathrm{C}}{ }^{\mathrm{c}} \\
0.24 \pm 0.00^{\mathrm{B}}{ }_{\mathrm{b}} \\
0.26 \pm 0.01^{\mathrm{A}}{ }^{\mathrm{b}} \\
0.25 \pm 0.00^{\mathrm{B}}{ }_{\mathrm{c}}\end{array}$ & $\begin{array}{l}0.99 \\
0.99 \\
1.00 \\
1.00 \\
1.00\end{array}$ & $\begin{array}{l}2.22 \pm 0.02^{\mathrm{A}} \mathrm{b} \\
1.69 \pm 0.01^{\mathrm{B}} \mathrm{b}^{\mathrm{b}} \\
1.33 \pm 0.04^{\mathrm{C}} \mathrm{b} \\
1.07 \pm 0.03^{\mathrm{D}} \mathrm{b} \\
0.78 \pm 0.04^{\mathrm{E}} \mathrm{b}^{\mathrm{b}}\end{array}$ & $\begin{array}{l}1.59 \\
1.42 \\
1.30 \\
1.81\end{array}$ \\
\hline $\begin{array}{l}\text { Vegetables } \\
\text { and chicken }\end{array}$ & $\begin{array}{l}5 \\
20 \\
35 \\
50 \\
65\end{array}$ & $\begin{array}{l}58.65 \pm 0.45^{\mathrm{A}}{ }^{\mathrm{a}} \\
52.48 \pm 0.61^{\mathrm{B}}{ }^{\mathrm{a}} \\
41.48 \pm 0.43^{\mathrm{C}^{\mathrm{a}}} \\
31.05 \pm 2.23^{\mathrm{D}}{ }^{\mathrm{a}} \\
22.50 \pm 0.46^{\mathrm{a}}\end{array}$ & $\begin{array}{l}0.27 \pm 0.00^{\mathrm{A}, \mathrm{B}}{ }_{\mathrm{d}} \\
0.26 \pm 0.01^{\mathrm{B}}{ }_{\mathrm{c}}^{\mathrm{c}} \\
0.26 \pm 0.00^{\mathrm{A}, \mathrm{B}^{\mathrm{C}}}{ }^{\mathrm{c}}{ }^{\mathrm{A}, 27} \pm 0.01^{\mathrm{A},{ }_{\mathrm{b}}} \\
0.28 \pm 0.00^{\mathrm{A}, \mathrm{c}}\end{array}$ & $\begin{array}{l}0.99 \\
0.99 \\
0.99 \\
0.99 \\
1.00\end{array}$ & $\begin{array}{l}14.26 \pm 0.19^{\mathrm{A}}{ }^{a} \\
10.93 \pm 0.53^{\mathrm{B}}{ }^{a} \\
7.94 \pm 1.28^{\mathrm{C}}{ }^{\mathrm{a}} \\
4.86 \pm 0.40^{\mathrm{D}}{ }^{\mathrm{a}} \\
2.40 \pm 0.17^{\mathrm{E}}{ }^{a}\end{array}$ & $\begin{array}{l}76.09 \pm 2.62^{\mathrm{A}}{ }^{\mathrm{a}} \\
64.36 \pm 3.96^{\mathrm{B}}{ }^{\mathrm{a}} \\
52.20 \pm 2.04^{\mathrm{C}}{ }^{\mathrm{a}} \\
39.20 \pm 0.94^{\mathrm{D}}{ }_{\mathrm{a}} \\
16.69 \pm 2.86^{\mathrm{a}}\end{array}$ & $\begin{array}{l}0.21 \pm 0.01^{\mathrm{B}}{ }^{\mathrm{c}} \\
0.21 \pm 0.00^{\mathrm{B}}{ }_{\mathrm{d}} \\
0.22 \pm 0.01^{\mathrm{B}}{ }^{\mathrm{c}} \\
0.22 \pm 0.01^{\mathrm{B}}{ }^{\mathrm{c}} \\
0.29 \pm 0.04^{\mathrm{A}}{ }_{\mathrm{b}}\end{array}$ & $\begin{array}{l}1.00 \\
0.99 \\
0.99 \\
0.99 \\
1.00\end{array}$ & $\begin{array}{l}3.29 \pm 0.02^{\mathrm{A}}{ }^{\mathrm{a}} \\
2.90 \pm 0.01^{\mathrm{B}}{ }^{\mathrm{a}} \\
2.23 \pm 0.02^{\mathrm{C}} \mathrm{a}^{\mathrm{a}} \\
1.74 \pm 0.10^{\mathrm{D}} \mathrm{a}^{\mathrm{a}} \\
1.28 \pm 0.00^{\mathrm{E}}{ }_{\mathrm{a}}\end{array}$ & $\begin{array}{l}0.79 \\
1.54 \\
1.46 \\
1.76\end{array}$ \\
\hline
\end{tabular}

${ }^{\mathrm{A}-\mathrm{E}}$ For the same column and for the same vegetable-based infant puree type and parameter means without the same letter are significantly different $(P<0.05)$ according to the LSD multiple range test.

${ }_{a-d}$ For the same column and for the same temperature and parameter means without the same letter are significantly different $(P<0.05)$ according to the LSD multiple range test.

Mean values $(n=6) \pm \mathrm{SD}$. 


\section{Table 3}

Experimental hysteresis area, relative thixotropic area values and rheological parameters of power law model describing flow downward curves of vegetable-based infant purees

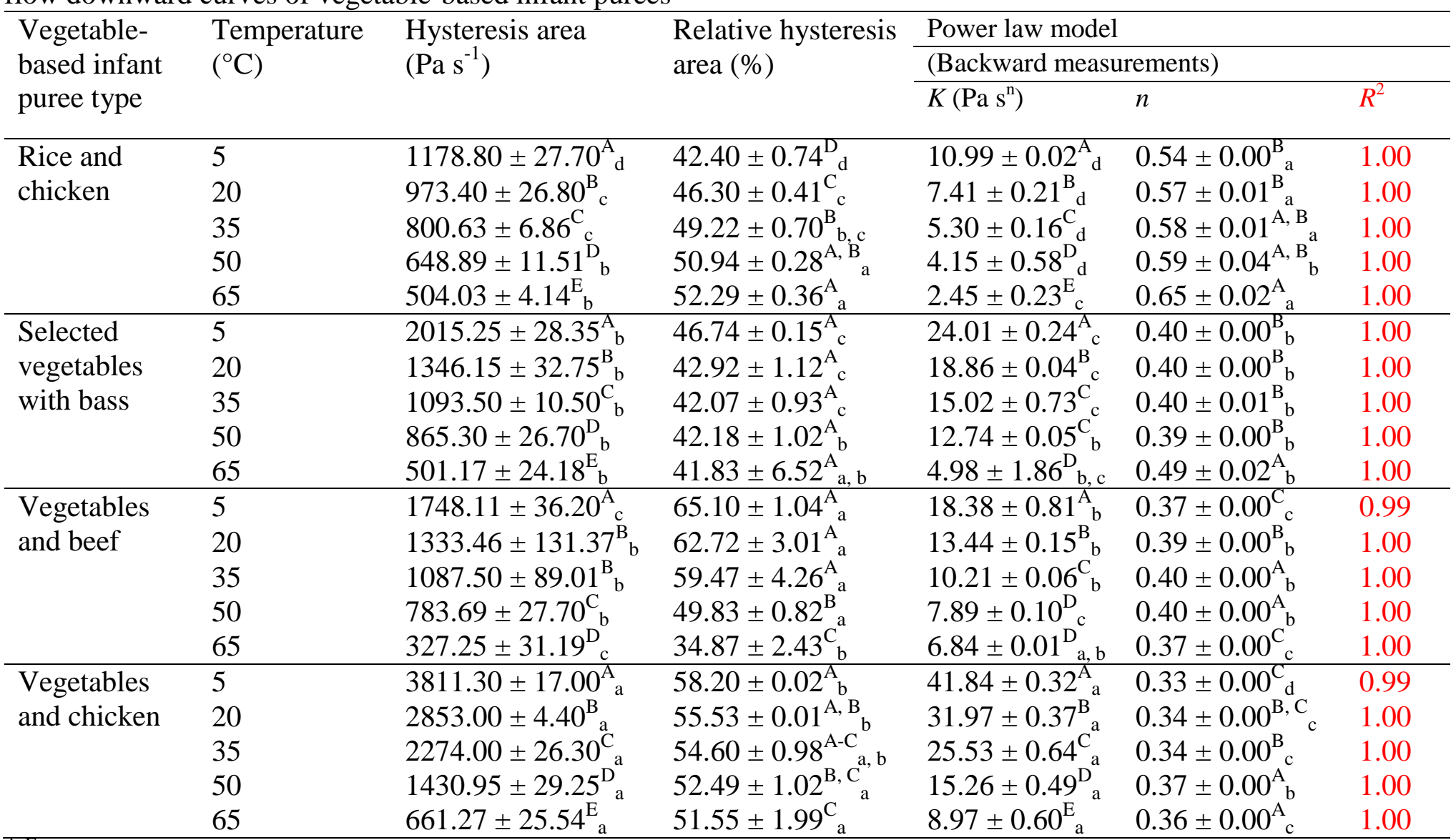

${ }^{\mathrm{A}-\mathrm{E}}$ For the same column and for the same vegetable-based infant puree type and parameter means without the same letter are significantly different $(P<0.05)$ according to the LSD multiple range test.

${ }_{\mathrm{a}-\mathrm{d}}$ For the same column and for the same temperature and parameter means without the same letter are significantly different $(P<0.05)$ according to the LSD multiple range test. Mean values $(n=3) \pm \mathrm{SD}$. 


\section{Table 4}

Parameters from Weltman and second-order structural kinetic models for rice and chicken infant puree at various temperatures and shear rates

\begin{tabular}{|c|c|c|c|c|c|c|c|}
\hline \multirow{2}{*}{$\begin{array}{l}\text { Temperature } \\
\left({ }^{\circ} \mathrm{C}\right)\end{array}$} & \multirow{2}{*}{$\begin{array}{l}\text { Shear } \\
\text { rate }\left(\mathrm{s}^{-1}\right)\end{array}$} & \multicolumn{3}{|l|}{ Weltman model } & \multicolumn{3}{|c|}{ Second-order structural kinetic model } \\
\hline & & $A(\mathrm{~Pa})$ & $-B(\mathrm{~Pa})$ & $R^{2}$ & $k \times 10^{2}\left(\mathrm{~s}^{-1}\right)$ & $\eta_{0} / \eta_{\mathrm{e}}$ & $R^{2}$ \\
\hline \multirow[t]{5}{*}{5} & 5 & $49.29 \pm 0.01_{\mathrm{e}}^{\mathrm{A}}$ & $2.33 \pm 0.02_{\mathrm{e}}^{\mathrm{A}}$ & 0.90 & $0.21 \pm 0.01_{\mathrm{e}}^{\mathrm{A}, \mathrm{B}}$ & $1.59 \pm 0.03^{\mathrm{C}, \mathrm{D}_{\mathrm{b}}}$ & 0.98 \\
\hline & 25 & $104.93 \pm 4.00_{\mathrm{d}}^{\mathrm{A}}$ & $7.05 \pm 0.04_{\mathrm{d}}^{\mathrm{A}}$ & 0.97 & $0.35 \pm 0.01_{\mathrm{d}}^{\mathrm{B}}$ & $2.14 \pm 0.04_{\mathrm{a}}^{\mathrm{A}}$ & 0.99 \\
\hline & 50 & $145.78 \pm 2.00_{c}^{\mathrm{A}}$ & $10.40 \pm 0.40^{\mathrm{A}}{ }_{c}$ & 0.98 & $0.42 \pm 0.02^{\mathrm{A}}{ }_{c}$ & $2.27 \pm 0.11_{a}^{\mathrm{B}}$ & 0.99 \\
\hline & 100 & $192.83 \pm 1.10^{\mathrm{A}}$ & $14.44 \pm 0.03^{\mathrm{A}} \mathrm{b}$ & 0.99 & $0.49 \pm 0.01_{b}^{\mathrm{A}}$ & $2.36 \pm 0.13^{\mathrm{B}}{ }_{\mathrm{a}}$ & 0.99 \\
\hline & 200 & $261.59 \pm 5.00_{a}^{\mathrm{A}}$ & $19.93 \pm 1.03_{\mathrm{a}}^{\mathrm{A}}$ & 0.99 & $0.58 \pm 0.02^{\mathrm{A}}$ & $2.38 \pm 0.01_{a}^{\mathrm{B}}$ & 0.99 \\
\hline \multirow[t]{5}{*}{20} & 5 & $28.44 \pm 1.40_{\mathrm{e}}^{\mathrm{B}}$ & $1.89 \pm 0.10_{\mathrm{e}}^{\mathrm{B}}$ & 0.82 & $0.15 \pm 0.03^{B}{ }_{d}^{a}$ & $1.38 \pm 0.07_{c}^{\mathrm{D}_{\mathrm{c}}}$ & 0.95 \\
\hline & 25 & $69.20 \pm 1.10_{\mathrm{d}}^{\mathrm{B}}$ & $3.90 \pm 0.10_{d}^{B}$ & 0.85 & $0.25 \pm 0.01^{\mathrm{C}}{ }_{\mathrm{c}}$ & $1.78 \pm 0.11_{b}^{\mathrm{B}}$ & 0.99 \\
\hline & 50 & $95.50 \pm 0.30^{B}{ }_{c}$ & $6.32 \pm 0.30^{\mathrm{B}}{ }_{\mathrm{c}}$ & 0.95 & $0.33 \pm 0.01_{b}^{\mathrm{B}}$ & $2.07 \pm 0.07_{\mathrm{a}, \mathrm{b}}^{\mathrm{B}}$ & 0.99 \\
\hline & 100 & $139.61 \pm 1.20^{\mathrm{B}}{ }_{\mathrm{b}}$ & $9.93 \pm 0.02^{\mathrm{B}}{ }_{\mathrm{b}}$ & 0.98 & $0.41 \pm 0.01_{\mathrm{a}}^{\mathrm{B}}$ & $2.25 \pm 0.12^{\mathrm{B}}$ & 0.99 \\
\hline & 200 & $191.18 \pm 1.18^{\mathrm{B}}{ }_{\mathrm{a}}^{\mathrm{C}}$ & $13.93 \pm 0.03^{\mathrm{B}}{ }_{\mathrm{a}}$ & 0.99 & $0.46 \pm 0.02_{\mathrm{a}}^{\mathrm{C}}$ & $2.36 \pm 0.03^{\mathrm{B}}{ }_{\mathrm{a}}^{\mathrm{a}}$ & 0.99 \\
\hline \multirow[t]{5}{*}{35} & 5 & $27.56 \pm 2.12^{\mathrm{B}} \mathrm{e}$ & $1.48 \pm 0.02_{\mathrm{D}}^{\mathrm{C}}$ & 0.95 & $0.30 \pm 0.03^{A}{ }_{d}$ & $1.72 \pm 0.12^{\mathrm{C}}{ }_{b}$ & 0.98 \\
\hline & 25 & $58.20 \pm 1.20_{\mathrm{d}}^{\mathrm{C}}$ & $3.94 \pm 0.03_{c, d}^{B}$ & 0.99 & $0.42 \pm 0.02_{c}^{\mathrm{A}}$ & $2.16 \pm 0.02_{\mathrm{a}, \mathrm{b}}^{\mathrm{A}}$ & 0.98 \\
\hline & 50 & $74.00 \pm 3.50^{\mathrm{C}_{c}}$ & $5.32 \pm 0.98_{\mathrm{b}, \mathrm{c}}^{\mathrm{B}}$ & 0.99 & $0.47 \pm 0.01_{b, c}^{\mathrm{A}}$ & $2.23 \pm 0.23^{\mathrm{B}}{ }_{\mathrm{a}}^{\mathrm{a}, \mathrm{c}}$ & 0.98 \\
\hline & 100 & $106.17 \pm 2.03_{\mathrm{b}}^{\mathrm{C}}$ & $7.75 \pm 1.20^{\mathrm{B}, \mathrm{C}_{\mathrm{a}, \mathrm{b}}}$ & 0.99 & $0.51 \pm 0.00_{\mathrm{b}}^{\mathrm{A}}$ & $2.32 \pm 0.11_{\mathrm{a}}^{\mathrm{B}}$ & 0.98 \\
\hline & 200 & $136.04 \pm 4.04_{\mathrm{a}}^{\mathrm{C}}$ & $9.75 \pm 0.10_{\mathrm{a}}^{\mathrm{C}}$ & 0.99 & $0.58 \pm 0.01^{\mathrm{A}, \mathrm{B}}{ }_{\mathrm{a}}$ & $2.35 \pm 0.03^{\mathrm{B}}{ }_{\mathrm{a}}$ & 0.98 \\
\hline \multirow[t]{5}{*}{50} & 5 & $17.39 \pm 0.81_{\mathrm{e}}^{\mathrm{C}}$ & $1.15 \pm 0.02^{\mathrm{D}}{ }_{\mathrm{d}}$ & 0.89 & $0.15 \pm 0.02^{\mathrm{B}}{ }_{\mathrm{d}}$ & $2.25 \pm 0.01^{\mathrm{B}}{ }_{\mathrm{c}}$ & 0.97 \\
\hline & 25 & $38.12 \pm 0.12^{D_{d}}$ & $2.46 \pm 0.40_{c, d}^{C}$ & 0.89 & $0.20 \pm 0.02_{c, d}^{C}$ & $2.26 \pm 0.11_{c}^{\mathrm{A}}$ & 0.98 \\
\hline & 50 & $54.93 \pm 2.03_{\mathrm{c}}^{\mathrm{D}}$ & $4.47 \pm 0.41_{b, c}^{B}$ & 0.90 & $0.25 \pm 0.02^{\mathrm{C}, \mathrm{c}}$ & $2.97 \pm 0.02^{\mathrm{A}} \mathrm{b}$ & 0.99 \\
\hline & 100 & $76.15 \pm 1.02^{\mathrm{D}}{ }_{\mathrm{b}}$ & $6.16 \pm 1.20^{\mathrm{C}, \mathrm{D}_{\mathrm{b}}}$ & 0.95 & $0.28 \pm 0.01_{\mathrm{a}, \mathrm{b}}^{\mathrm{C}}$ & $3.03 \pm 0.10^{\mathrm{A}}{ }_{\mathrm{b}}$ & 0.99 \\
\hline & 200 & $110.75 \pm 5.22^{\mathrm{D}}{ }_{\mathrm{a}}$ & $9.70 \pm 0.20_{\mathrm{a}}^{\mathrm{C}}$ & 0.96 & $0.33 \pm 0.01_{a}^{\mathrm{D}}$ & $3.43 \pm 0.13^{\mathrm{A}}$ & 0.99 \\
\hline \multirow[t]{6}{*}{65} & 5 & $13.57 \pm 1.12_{\mathrm{e}}^{\mathrm{C}}$ & $1.17 \pm 0.01_{c}^{\mathrm{D}_{\mathrm{c}}}$ & 0.90 & $0.27 \pm 0.03^{\mathrm{A}_{\mathrm{c}}^{\mathrm{a}}}$ & $3.31 \pm 0.11_{\mathrm{a}}^{\mathrm{A}}$ & 0.98 \\
\hline & 25 & $28.89 \pm 2.10_{\mathrm{d}}^{\mathrm{E}}$ & $1.78 \pm 0.12^{\mathrm{C}} \mathrm{b}, \mathrm{c}$ & 0.98 & $0.39 \pm 0.01^{\mathrm{A}, \mathrm{B}}{ }_{\mathrm{b}}$ & $2.08 \pm 0.08^{\mathrm{A}_{\mathrm{b}}^{\mathrm{a}}}$ & 0.97 \\
\hline & 50 & $39.16 \pm 1.03^{\mathrm{E}}{ }_{\mathrm{c}}$ & $2.33 \pm 0.23_{\mathrm{a}-\mathrm{c}}^{\mathrm{C}}$ & 0.99 & $0.44 \pm 0.02_{\mathrm{b}}^{\mathrm{A}}$ & $1.95 \pm 0.01^{\mathrm{B}}{ }_{\mathrm{b}, \mathrm{c}}$ & 0.98 \\
\hline & 100 & $54.64 \pm 1.32^{\mathrm{E}}{ }_{\mathrm{b}}$ & $3.47 \pm 0.22^{\mathrm{D}} \mathrm{a}, \mathrm{b}$ & 0.98 & $0.40 \pm 0.02_{\mathrm{a}, \mathrm{b}}^{\mathrm{B}}$ & $1.97 \pm 0.12^{\mathrm{B}} \mathrm{b}, \mathrm{c}$ & 0.99 \\
\hline & 200 & $72.58 \pm 0.40^{\mathrm{E}}$ & $3.77 \pm 1.10^{D_{a}}$ & 0.98 & $0.51 \pm 0.03^{\mathrm{B}, \mathrm{C}}$ & $1.70 \pm 0.02^{\mathrm{C}}{ }_{\mathrm{c}}$ & 0.96 \\
\hline & & \multicolumn{6}{|c|}{ Power law models } \\
\hline \multirow[t]{2}{*}{5} & & \multicolumn{2}{|l|}{$A=24.16 \dot{\gamma}^{0.453}$} & 1.00 & $k=1.39 \times 10^{-3} \gamma^{0.275}$ & & 0.99 \\
\hline & & \multicolumn{2}{|l|}{$B=0.985 \dot{\gamma}^{0.583}$} & 0.99 & & & \\
\hline \multirow[t]{2}{*}{20} & & \multicolumn{2}{|l|}{$A=12.62 \dot{\gamma}^{0.518}$} & 1.00 & $k=9.20 \times 10^{-4} \dot{\gamma}^{0.315}$ & & 0.99 \\
\hline & & \multicolumn{2}{|l|}{$B=0.732 \dot{\gamma}^{0.554}$} & 0.99 & & & \\
\hline \multirow[t]{2}{*}{35} & & \multicolumn{2}{|l|}{$A=13.88 \dot{\gamma}^{0.435}$} & 1.00 & $k=2.31 \times 10^{-3} \gamma^{0.176}$ & & 0.99 \\
\hline & & \multicolumn{2}{|l|}{$B=0.686 \dot{\gamma}^{0.517}$} & 0.99 & & & \\
\hline \multirow[t]{2}{*}{50} & & \multicolumn{2}{|l|}{$A=7.71 \dot{\gamma}^{0.500}$} & 1.00 & $k=1.04 \times 10^{-3} \dot{\gamma}^{0.216}$ & & 0.99 \\
\hline & & \multicolumn{2}{|l|}{$B=0.427 \dot{\gamma}^{0.584}$} & 0.99 & & & \\
\hline \multirow[t]{2}{*}{65} & & \multirow{2}{*}{\multicolumn{2}{|c|}{$\begin{aligned} A & =6.57 \dot{\gamma}^{0.457} \\
B & =0.653 \dot{\gamma}^{0.337}\end{aligned}$}} & 1.00 & $k=2.12 \times 10^{-3} \dot{\gamma}^{0.177}$ & & 0.97 \\
\hline & & & & 0.97 & & & \\
\hline Arrehnius & 5 & $A / \dot{\gamma}=1927.2 \dot{\gamma}-$ & $4.69 ; E_{\mathrm{a}}=16.02 \mathrm{~kJ}$ & $\mathrm{ol}^{-1}$ & & & 0.95 \\
\hline model & 25 & $A / \dot{\gamma}=1987.6 \dot{\gamma}-$ & $5.71 ; E_{\mathrm{a}}=16.52 \mathrm{~kJ}$ & $\mathrm{ol}^{-1}$ & & & 0.99 \\
\hline & 50 & $A / \dot{\gamma}=1993.9 \dot{\gamma}-$ & $5.11 ; E_{\mathrm{a}}=16.58 \mathrm{~kJ}$ & $\mathrm{ol}^{-1}$ & & & 0.99 \\
\hline & 100 & $A / \dot{\gamma}=1954.6 \dot{\gamma}-$ & $5.34 ; E_{\mathrm{a}}=16.25 \mathrm{~kJ}$ & $\mathrm{ol}^{-1}$ & & & 0.99 \\
\hline & 200 & $A / \dot{\gamma}=1943.3 \dot{\gamma}-$ & $5.69 ; E_{\mathrm{a}}=16.16 \mathrm{~kJ}$ & $\mathrm{ol}^{-1}$ & & & 0.99 \\
\hline
\end{tabular}

\footnotetext{
${ }^{\mathrm{A}-\mathrm{E}}$ For the same column and for the same shear rate and parameter means without the same letter are significantly different $(P<0.05)$ according to the LSD multiple range test.

a-d For the same column and for the same temperature and parameter means without the same letter are significantly different $(P<0.05)$ according to the LSD multiple range test. Mean values $(n=3) \pm \mathrm{SD}$.
} 
Table 5

Parameters from Weltman and second-order structural kinetic models for selected vegetables with bass infant puree at various temperatures and shear rates

\begin{tabular}{|c|c|c|c|c|c|c|c|}
\hline \multirow{2}{*}{$\begin{array}{l}\text { Temperature } \\
\left({ }^{\circ} \mathrm{C}\right)\end{array}$} & \multirow{2}{*}{$\begin{array}{l}\text { Shear } \\
\text { rate }\left(\mathrm{s}^{-1}\right)\end{array}$} & \multicolumn{3}{|l|}{ Weltman model } & \multicolumn{3}{|c|}{ Second-order structural kinetic model } \\
\hline & & $A(\mathrm{~Pa})$ & $-B(\mathrm{~Pa})$ & $R^{2}$ & $k \times 10^{2}\left(\mathrm{~s}^{-1}\right)$ & $\eta_{0} / \eta_{\mathrm{e}}$ & $R^{2}$ \\
\hline \multirow[t]{5}{*}{5} & 5 & $95.25 \pm 1.10_{\mathrm{e}}^{\mathrm{A}}$ & $5.44 \pm 0.33^{\mathrm{A}}$ & 0.97 & $0.36 \pm 0.03_{\mathrm{e}}^{\mathrm{A}}$ & $1.87 \pm 0.11_{b}^{\mathrm{A}}$ & 0.97 \\
\hline & 25 & $144.78 \pm 3.10^{A}{ }_{d}$ & $10.48 \pm 0.48^{\mathrm{A}}$ & 0.99 & $0.52 \pm 0.01_{\mathrm{d}}^{\mathrm{A}}$ & $2.23 \pm 0.13^{\mathrm{A}} \mathrm{a}, \mathrm{b}$ & 0.99 \\
\hline & 50 & $174.77 \pm 14.02_{c}^{\mathrm{A}}$ & $12.67 \pm 1.10_{\mathrm{b}, \mathrm{c}}^{\mathrm{A}}$ & 0.99 & $0.61 \pm 0.01_{c}^{\mathrm{A}}$ & $2.36 \pm 0.03^{\mathrm{A}}{ }_{\mathrm{a}}^{\mathrm{a}}$ & 0.99 \\
\hline & 100 & $205.88 \pm 1.11_{\mathrm{b}}^{\mathrm{A}}$ & $14.49 \pm 0.12^{\mathrm{A}} \mathrm{b}$ & 0.99 & $0.72 \pm 0.02_{b}^{C_{b}}$ & $2.32 \pm 0.11_{\mathrm{a}}^{\mathrm{A}}$ & 0.99 \\
\hline & 200 & $249.42 \pm 4.22^{\mathrm{A}}{ }_{a}$ & $17.43 \pm 1.12_{\mathrm{a}}^{\mathrm{A}}$ & 1.00 & $0.86 \pm 0.02^{\mathrm{B}, \mathrm{C}}$ & $2.43 \pm 0.12^{\mathrm{A}} \mathrm{a}$ & 0.99 \\
\hline \multirow[t]{5}{*}{20} & 5 & $68.17 \pm 1.12^{\mathrm{B}}{ }_{\mathrm{d}}^{\mathrm{a}}$ & $2.99 \pm 0.01^{\mathrm{B}}{ }_{\mathrm{d}}^{\mathrm{a}}$ & 0.94 & $0.23 \pm 0.01^{\mathrm{A}}{ }_{\mathrm{e}}^{\mathrm{a}}$ & $1.64 \pm 0.10^{\mathrm{A}, \mathrm{B}}{ }_{\mathrm{b}}$ & 0.90 \\
\hline & 25 & $113.25 \pm 13.04^{\mathrm{B}} \mathrm{c}$ & $7.75 \pm 0.21_{c}^{\mathrm{B}}$ & 0.99 & $0.40 \pm 0.01_{d}^{B}$ & $2.18 \pm 0.02^{\mathrm{A}}$ & 0.99 \\
\hline & 50 & $128.68 \pm 4.10^{\mathrm{B}}{ }_{\mathrm{c}}$ & $8.94 \pm 0.11_{c}^{B}$ & 0.98 & $0.47 \pm 0.02^{C}{ }_{c}$ & $2.19 \pm 0.04^{\mathrm{B}}{ }_{\mathrm{a}}$ & 0.99 \\
\hline & 100 & $167.47 \pm 1.47_{b}^{\mathrm{B}}$ & $12.08 \pm 1.01_{b}^{\mathrm{B}}$ & 1.00 & $0.57 \pm 0.01_{b}^{\mathrm{D}}$ & $2.26 \pm 0.12^{\mathrm{A}, \mathrm{B}}$ & 0.99 \\
\hline & 200 & $201.44 \pm 2.11_{\mathrm{a}}^{\mathrm{B}}$ & $14.23 \pm 0.12^{\mathrm{B}}{ }_{\mathrm{a}}$ & 1.00 & $0.77 \pm 0.01^{\mathrm{C}, \mathrm{D}_{\mathrm{a}}}$ & $2.39 \pm 0.02_{\mathrm{a}}^{\mathrm{A}}$ & 0.99 \\
\hline \multirow[t]{5}{*}{35} & 5 & $48.97 \pm 1.02^{\mathrm{C}} \mathrm{e}^{-1}$ & $1.68 \pm 0.11_{\mathrm{d}}^{\mathrm{C}}$ & 0.88 & $0.27 \pm 0.01_{\mathrm{d}}^{\mathrm{A}}$ & $1.38 \pm 0.10^{\mathrm{B}}{ }_{\mathrm{c}}$ & 0.98 \\
\hline & 25 & $83.47 \pm 2.40_{\mathrm{d}}^{\mathrm{C}_{\mathrm{C}}}$ & $5.28 \pm 0.51_{c}^{\mathrm{C}}$ & 0.96 & $0.40 \pm 0.02^{\mathrm{B}}{ }_{\mathrm{c}, \mathrm{d}}$ & $1.94 \pm 0.03^{\mathrm{A}, \mathrm{B}}{ }_{\mathrm{b}}$ & 0.99 \\
\hline & 50 & $106.73 \pm 3.02^{\mathrm{B}, \mathrm{C}_{\mathrm{c}}}$ & $6.97 \pm 0.02^{\mathrm{C}}{ }_{\mathrm{c}}$ & 0.98 & $0.46 \pm 0.01_{b, c}^{\mathrm{C}, \mathrm{c}}$ & $2.03 \pm 0.03_{a, b}^{C}$ & 0.99 \\
\hline & 100 & $133.61 \pm 5.10_{\mathrm{b}}^{\mathrm{C}}$ & $9.16 \pm 0.16^{C_{b}}$ & 0.99 & $0.58 \pm 0.01_{\mathrm{a}, \mathrm{b}}^{\mathrm{D}}$ & $2.23 \pm 0.12^{\mathrm{A}, \mathrm{B}} \mathrm{a}, \mathrm{b}$ & 0.99 \\
\hline & 200 & $164.80 \pm 2.10_{\mathrm{a}}^{\mathrm{C}}$ & $11.64 \pm 1.02^{\mathrm{C}}{ }_{\mathrm{a}}$ & 1.00 & $0.73 \pm 0.03^{\mathrm{D}}$ & $2.26 \pm 0.11_{\mathrm{a}}^{\mathrm{A}}$ & 0.99 \\
\hline \multirow[t]{5}{*}{50} & 5 & $40.70 \pm 1.20_{\mathrm{e}}^{\mathrm{D}}$ & $1.58 \pm 0.11_{\mathrm{d}^{\mathrm{a}}}^{\mathrm{C}^{\mathrm{a}}}$ & 0.91 & $0.31 \pm 0.03^{\mathrm{A}_{\mathrm{e}}}$ & $1.46 \pm 0.07^{\mathrm{B}}{ }_{\mathrm{c}}^{\mathrm{a}}$ & 0.96 \\
\hline & 25 & $67.14 \pm 1.01{ }^{\mathrm{C}, \mathrm{D}_{\mathrm{d}}}$ & $3.46 \pm 0.46^{\mathrm{D}}$ & 0.99 & $0.55 \pm 0.02^{\mathrm{A}}{ }_{\mathrm{d}}$ & $1.69 \pm 0.11_{b, c}^{\mathrm{B}}$ & 0.99 \\
\hline & 50 & $83.40 \pm 2.20^{\mathrm{C}, \mathrm{D}_{\mathrm{c}}}$ & $4.55 \pm 0.12^{\mathrm{D}, \mathrm{c}}$ & 0.99 & $0.66 \pm 0.01_{c}^{\mathrm{A}}$ & $1.77 \pm 0.03^{\mathrm{D}} \mathrm{a}, \mathrm{b}$ & 0.99 \\
\hline & 100 & $101.49 \pm 0.40_{b}^{\mathrm{D}}$ & $6.02 \pm 1.02^{\mathrm{D}} \mathrm{a}, \mathrm{b}$ & 0.99 & $0.81 \pm 0.01_{b}^{\mathrm{B}}$ & $1.96 \pm 0.01^{\mathrm{B}, \mathrm{C}}$ & 0.99 \\
\hline & 200 & $128.06 \pm 2.03^{\mathrm{D}} \mathrm{a}$ & $7.77 \pm 0.22_{a}^{\mathrm{D}}$ & 0.99 & $0.90 \pm 0.02^{\mathrm{B}} \mathrm{a}$ & $1.98 \pm 0.02_{\mathrm{a}}^{\mathrm{B}}$ & 0.99 \\
\hline \multirow[t]{6}{*}{65} & 5 & $27.68 \pm 1.20^{\mathrm{E}_{\mathrm{e}}^{\mathrm{a}}}$ & $0.93 \pm 0.03^{\mathrm{D}^{\mathrm{a}}}$ & 0.81 & Not applicable & & \\
\hline & 25 & $45.40 \pm 3.10_{\mathrm{d}}^{\mathrm{D}}$ & $1.38 \pm 0.11_{\mathrm{d}}^{\mathrm{E}}$ & 0.88 & Not applicable & & \\
\hline & 50 & $61.30 \pm 1.80_{c}^{\mathrm{D}}$ & $2.93 \pm 0.10_{c}^{\mathrm{D}}$ & 0.94 & Not applicable & & \\
\hline & 100 & $73.60 \pm 3.10^{\mathrm{E}}{ }_{\mathrm{b}}^{\mathrm{c}}$ & $3.84 \pm 0.20^{D_{b}}$ & 0.90 & $1.02 \pm 0.03_{\mathrm{b}}^{\mathrm{A}}$ & $1.82 \pm 0.02^{\mathrm{C}}{ }_{\mathrm{b}}$ & 0.97 \\
\hline & 200 & $92.01 \pm 2.00^{\mathrm{E}}$ & $5.16 \pm 0.10_{\mathrm{a}}^{\mathrm{E}}$ & 0.90 & $1.69 \pm 0.05_{\mathrm{a}}^{\mathrm{A}}$ & $2.53 \pm 0.04_{\mathrm{a}}^{\mathrm{A}}$ & 0.99 \\
\hline & & \multicolumn{6}{|c|}{ Power law and logarithmic models } \\
\hline \multirow[t]{2}{*}{5} & & \multicolumn{2}{|l|}{$A=62.74 \dot{\gamma}^{0.260}$} & 1.00 & \multirow{2}{*}{\multicolumn{2}{|c|}{$k=2.45 \times 10^{-3} \dot{\gamma}^{0.235}$}} & 1.00 \\
\hline & & \multicolumn{2}{|c|}{$B=3.18 \ln (\dot{\gamma})+0.239$} & 1.00 & & & \\
\hline \multirow[t]{2}{*}{20} & & \multicolumn{2}{|l|}{$A=42.77 \dot{\gamma}^{0.293}$} & 1.00 & \multicolumn{2}{|c|}{$k=1.39 \times 10^{-3} \dot{\gamma}^{0.317}$} & 0.99 \\
\hline & & \multicolumn{2}{|c|}{$B=3.03 \ln (\dot{\gamma})-2.091$} & 0.99 & & & \\
\hline \multirow[t]{2}{*}{35} & & \multicolumn{2}{|c|}{$A=28.38 \dot{\gamma}^{0.340}$} & 0.99 & \multicolumn{2}{|c|}{$k=1.72 \times 10^{-3} \dot{\gamma}^{0.265}$} & 0.99 \\
\hline & & \multicolumn{2}{|c|}{$B=2.66 \ln (\dot{\gamma})-2.971$} & 0.99 & & & \\
\hline \multirow[t]{2}{*}{50} & & \multicolumn{2}{|l|}{$A=24.78 \dot{\gamma}^{0.309}$} & 1.00 & $k=2.02 \times 10^{-3} \dot{\gamma}^{0}$ & & 0.98 \\
\hline & & $B=0.818 \dot{\gamma}^{0.423}$ & & 1.00 & & & \\
\hline 65 & & $A=16.26 \dot{\gamma}^{0.329}$ & & 1.00 & Not applicable & & \\
\hline & & $B=0.379 \dot{\gamma}^{0.492}$ & & 0.95 & & & \\
\hline Arrehnius & 5 & $A / \dot{\gamma}=1870.4 \dot{\gamma}-3$ & $7 ; E_{\mathrm{a}}=15.55 \mathrm{~kJ} \mathrm{r}$ & & & & 0.99 \\
\hline model & 25 & $A / \dot{\gamma}=1772.0 \dot{\gamma}-4$ & $7 ; E_{\mathrm{a}}=14.73 \mathrm{~kJ} \mathrm{r}$ & & & & 0.98 \\
\hline & 50 & $A / \dot{\gamma}=1580.4 \dot{\gamma}-4$ & $3 ; E_{\mathrm{a}}=13.14 \mathrm{~kJ} \mathrm{r}$ & & & & 0.99 \\
\hline & 100 & $A / \dot{\gamma}=1591.9 \dot{\gamma}-4$ & $4 ; E_{\mathrm{a}}=13.24 \mathrm{~kJ} \mathrm{r}$ & & & & 0.98 \\
\hline & 200 & $A / \dot{\gamma}=1522.5 \dot{\gamma}-5$ & $0 ; E_{\mathrm{a}}=12.66 \mathrm{~kJ} \mathrm{r}$ & & & & 0.98 \\
\hline
\end{tabular}

${ }^{\mathrm{A}-\mathrm{E}}$ For the same column and for the same shear rate and parameter means without the same letter are significantly different $(P<0.05)$ according to the LSD multiple range test.

${ }_{\text {a-d }}$ For the same column and for the same temperature and parameter means without the same letter are significantly different $(P<0.05)$ according to the LSD multiple range test. Mean values $(n=3) \pm \mathrm{SD}$. 


\section{Table 6}

Parameters from Weltman and second-order structural kinetic models for vegetables and beef puree at various temperatures and shear rates

\begin{tabular}{|c|c|c|c|c|c|c|c|}
\hline \multirow{2}{*}{$\begin{array}{l}\text { Temperature } \\
\left({ }^{\circ} \mathrm{C}\right)\end{array}$} & \multirow{2}{*}{$\begin{array}{l}\text { Shear } \\
\text { rate }\left(\mathrm{s}^{-1}\right)\end{array}$} & \multicolumn{3}{|l|}{ Weltman model } & \multicolumn{3}{|c|}{ Second-order structural kinetic model } \\
\hline & & $A(\mathrm{~Pa})$ & $-B(\mathrm{~Pa})$ & $R^{2}$ & $k \times 10^{2}\left(\mathrm{~s}^{-1}\right)$ & $\eta_{0} / \eta_{\mathrm{e}}$ & $R^{2}$ \\
\hline \multirow[t]{5}{*}{5} & 5 & $60.33 \pm 0.03^{\mathrm{A}}$ & $2.49 \pm 0.11_{c}^{\mathrm{A}}$ & 0.95 & $0.35 \pm 0.03^{\mathrm{A}}$ & $1.53 \pm 0.12^{\mathrm{A}}{ }_{\mathrm{b}}$ & 0.93 \\
\hline & 25 & $100.93 \pm 2.02^{\mathrm{A}}{ }_{\mathrm{d}}$ & $6.36 \pm 0.36_{b}^{\mathrm{A}}$ & 0.99 & $0.56 \pm 0.01^{\mathrm{A}, \mathrm{B}}{ }_{\mathrm{d}}$ & $1.96 \pm 0.03^{\mathrm{A}}$ & 0.99 \\
\hline & 50 & $121.07 \pm 3.02^{\mathrm{A}}{ }_{c}$ & $7.82 \pm 0.10^{\mathrm{B}}$ & 1.00 & $0.61 \pm 0.04_{c}^{\mathrm{A}}$ & $2.04 \pm 0.04_{a}^{C^{a}}$ & 0.99 \\
\hline & 100 & $153.26 \pm 4.02^{\mathrm{A}} \mathrm{b}$ & $10.03 \pm 1.03^{\mathrm{A}, \mathrm{B}}{ }_{\mathrm{a}}$ & 1.00 & $0.72 \pm 0.02^{\mathrm{A}} \mathrm{b}$ & $2.09 \pm 0.05^{\mathrm{C}}$ & 0.98 \\
\hline & 200 & $188.44 \pm 3.86_{a}^{\mathrm{A}}$ & $11.59 \pm 0.30_{\mathrm{a}}^{\mathrm{A}}$ & 1.00 & $0.95 \pm 0.03^{\mathrm{A}}$ & $2.13 \pm 0.05^{\mathrm{B}}$ & 0.98 \\
\hline \multirow[t]{5}{*}{20} & 5 & $53.16 \pm 1.05^{\mathrm{B}} \mathrm{e}^{\mathrm{a}}$ & $2.05 \pm 0.05_{c}^{\mathrm{B}}$ & 0.88 & $0.28 \pm 0.04_{d}^{\mathrm{A}}$ & $1.46 \pm 0.10^{\mathrm{A}_{\mathrm{c}}^{\mathrm{a}}}$ & 0.97 \\
\hline & 25 & $92.72 \pm 2.12^{\mathrm{B}}{ }_{\mathrm{d}}$ & $6.43 \pm 0.33_{b}^{A}$ & 0.96 & $0.40 \pm 0.01^{\mathrm{A}, \mathrm{B}_{\mathrm{c}, \mathrm{d}}}$ & $2.15 \pm 0.05_{\mathrm{b}}^{\mathrm{A}}$ & 0.99 \\
\hline & 50 & $114.60 \pm 3.80^{\mathrm{A}}{ }_{\mathrm{c}}$ & $8.32 \pm 0.18^{\mathrm{A}} \mathrm{b}$ & 0.98 & $0.48 \pm 0.01_{b, c}^{\mathrm{B}}$ & $2.30 \pm 0.03^{\mathrm{A}}{ }_{\mathrm{b}}$ & 0.99 \\
\hline & 100 & $144.06 \pm 1.02^{\mathrm{B}} \mathrm{b}$ & $11.14 \pm 1.10_{\mathrm{a}}^{\mathrm{A}}$ & 1.00 & $0.59 \pm 0.02^{\mathrm{B}}{ }_{\mathrm{a}, \mathrm{b}}^{\mathrm{b}}$ & $2.56 \pm 0.01_{a}^{\mathrm{A}}$ & 0.99 \\
\hline & 200 & $168.61 \pm 1.99^{\mathrm{B}}{ }_{\mathrm{a}}$ & $12.12 \pm 0.12^{\mathrm{A}_{\mathrm{a}}^{\mathrm{a}}}$ & 0.99 & $0.73 \pm 0.03^{\mathrm{B}}{ }_{\mathrm{a}}^{\mathrm{a}, \mathrm{C}}$ & $2.68 \pm 0.06^{\mathrm{A}^{\mathrm{a}}}$ & 0.99 \\
\hline \multirow[t]{5}{*}{35} & 5 & $40.49 \pm 1.21_{\mathrm{e}}^{\mathrm{C}}$ & $1.57 \pm 0.20_{\mathrm{e}}^{\mathrm{C}}$ & 0.88 & $0.26 \pm 0.02_{\mathrm{A}}^{\mathrm{A}}$ & $1.44 \pm 0.11^{\mathrm{A}}{ }_{\mathrm{c}}$ & 0.99 \\
\hline & 25 & $68.79 \pm 2.20_{\mathrm{d}}^{\mathrm{C}}$ & $4.50 \pm 0.15^{\mathrm{B}}{ }_{\mathrm{d}}$ & 0.96 & $0.37 \pm 0.01^{B}{ }_{d}$ & $2.09 \pm 0.06_{\mathrm{b}}^{\mathrm{A}}$ & 0.99 \\
\hline & 50 & $83.51 \pm 1.14^{\mathrm{B}}{ }_{\mathrm{c}}$ & $5.82 \pm 0.12_{c}^{\mathrm{C}}$ & 0.98 & $0.48 \pm 0.01_{c}^{\mathrm{B}}$ & $2.16 \pm 0.03^{B}{ }_{b}^{B}$ & 0.99 \\
\hline & 100 & $105.29 \pm 1.09^{C_{b}}$ & $7.60 \pm 0.10_{b}^{B}$ & 1.00 & $0.57 \pm 0.01_{b}^{\mathrm{B}}$ & $2.27 \pm 0.02^{\mathrm{B}}{ }_{\mathrm{a}, \mathrm{b}}$ & 0.99 \\
\hline & 200 & $126.20 \pm 4.01^{\mathrm{C}}{ }_{\mathrm{a}}$ & $9.06 \pm 0.06_{\mathrm{a}}^{\mathrm{B}}$ & 0.99 & $0.73 \pm 0.02^{\mathrm{B}}{ }_{\mathrm{a}}$ & $2.45 \pm 0.04^{\mathrm{A}, \mathrm{B}}$ & 0.99 \\
\hline \multirow[t]{5}{*}{50} & 5 & $28.00 \pm 1.02_{\mathrm{e}}^{\mathrm{D}}$ & $1.11 \pm 0.10^{\mathrm{D}}$ & 0.96 & $0.42 \pm 0.06^{A}{ }_{d}^{A}$ & $1.51 \pm 0.10_{\mathrm{c}}^{\mathrm{A}}$ & 0.91 \\
\hline & 25 & $48.68 \pm 2.31_{d}^{D_{d}}$ & $2.48 \pm 0.40^{C}$ & 0.99 & $0.59 \pm 0.04_{c}^{\mathrm{A}}$ & $1.68 \pm 0.10_{b, c}^{\mathrm{B}}$ & 0.99 \\
\hline & 50 & $64.19 \pm 1.10^{\mathrm{C}}{ }_{\mathrm{c}}$ & $3.94 \pm 0.13_{c}^{D}$ & 0.99 & $0.64 \pm 0.01_{b, c}^{\mathrm{A}}$ & $1.89 \pm 0.01_{a, b}^{\mathrm{D}}$ & 0.99 \\
\hline & 100 & $78.06 \pm 2.03^{D_{b}}$ & $4.86 \pm 0.14_{\mathrm{b}}^{\mathrm{C}}$ & 0.99 & $0.73 \pm 0.02^{\mathrm{A}}{ }_{\mathrm{b}}$ & $1.95 \pm 0.00_{a, b}^{\mathrm{D}}$ & 0.99 \\
\hline & 200 & $98.28 \pm 1.27_{\mathrm{a}}^{\mathrm{D}}$ & $6.45 \pm 0.32^{\mathrm{C}}$ & 0.98 & $0.97 \pm 0.01_{\mathrm{a}}^{\mathrm{A}}$ & $2.14 \pm 0.14^{\mathrm{B}}{ }_{\mathrm{a}}^{\mathrm{a}}$ & 0.99 \\
\hline \multirow[t]{6}{*}{65} & 5 & $21.50 \pm 1.40_{\mathrm{e}}^{\mathrm{E}}$ & $0.72 \pm 0.02^{D_{d}^{a}}$ & 0.84 & Not applicable & & \\
\hline & 25 & $34.18 \pm 1.02^{\mathrm{E}}{ }_{\mathrm{d}}$ & $1.82 \pm 0.12^{\mathrm{C}}{ }_{\mathrm{c}}^{\mathrm{a}}$ & 0.96 & Not applicable & & \\
\hline & 50 & $40.19 \pm 1.01_{c}^{\mathrm{D}}$ & $2.12 \pm 0.01_{b}^{\mathrm{E}}$ & 0.97 & $0.50 \pm 0.02^{\mathrm{B}}{ }_{\mathrm{b}}$ & $1.91 \pm 0.04_{\mathrm{a}}^{\mathrm{D}}$ & 0.99 \\
\hline & 100 & $51.78 \pm 0.11_{b}^{\mathrm{E}}$ & $3.01 \pm 0.00_{a}^{C}$ & 0.99 & $0.67 \pm 0.01_{a}^{\mathrm{A}}$ & $1.93 \pm 0.03^{\mathrm{D}} \mathrm{a}$ & 0.99 \\
\hline & 200 & $63.67 \pm 0.33^{\mathrm{E}}{ }_{\mathrm{a}}$ & $3.16 \pm 0.12^{\mathrm{D}}{ }_{\mathrm{a}}$ & 0.92 & Not applicable & & \\
\hline & & \multicolumn{6}{|c|}{ Power law and logarithmic models } \\
\hline \multirow[t]{2}{*}{5} & & \multicolumn{2}{|l|}{$A=36.87 \dot{\gamma}^{0.308}$} & 1.00 & \multirow{2}{*}{\multicolumn{2}{|c|}{$k=2.32 \times 10^{-3} \dot{\gamma}^{0.257}$}} & 0.98 \\
\hline & & \multicolumn{2}{|c|}{$B=2.48 \ln (\dot{\gamma})-1.595$} & 1.00 & & & \\
\hline \multirow[t]{2}{*}{20} & & \multicolumn{2}{|l|}{$A=32.65 \dot{\gamma}^{0.317}$} & 1.00 & \multirow{2}{*}{\multicolumn{2}{|c|}{$k=1.79 \times 10^{-3} \dot{\gamma}^{0.259}$}} & 0.99 \\
\hline & & \multicolumn{2}{|c|}{$B=2.83 \ln (\dot{\gamma})-2.541$} & 0.99 & & & \\
\hline \multirow[t]{2}{*}{35} & & \multicolumn{2}{|l|}{$A=24.90 \gamma^{0.310}$} & 1.00 & $k=1.60 \times 10^{-3} \dot{\gamma}^{0.279}$ & & 0.99 \\
\hline & & \multicolumn{2}{|c|}{$B=2.04 \ln (\dot{\gamma})-1.883$} & 1.00 & & & \\
\hline \multirow[t]{2}{*}{50} & & \multicolumn{2}{|l|}{$A=16.29 \dot{\gamma}^{0.342}$} & 1.00 & $k=2.93 \times 10^{-3} \dot{\gamma}^{0.212}$ & & 0.97 \\
\hline & & \multicolumn{2}{|l|}{$B=0.528 \dot{\gamma}^{0.484}$} & 0.99 & & & \\
\hline 65 & & $A=13.26 \dot{\gamma}^{0.293}$ & & 1.00 & Not applicable & & \\
\hline & & $B=0.69 \ln (\dot{\gamma})-($ & 407 & 0.98 & & & \\
\hline Arrehnius & 5 & $A / \dot{\gamma}=1680.4 \dot{\gamma}-$ & $3.45 ; E_{\mathrm{a}}=13.97 \mathrm{~kJ}$ & $\mathrm{ol}^{-1}$ & & & 0.96 \\
\hline model & 25 & $A / \dot{\gamma}=1739.8 \dot{\gamma}-$ & $4.73 ; E_{\mathrm{a}}=14.46 \mathrm{~kJ}$ & $1 \mathrm{ol}^{-1}$ & & & 0.94 \\
\hline & 50 & $A / \dot{\gamma}=1718.8 \dot{\gamma}-$ & $5.15 ; E_{\mathrm{a}}=14.29 \mathrm{~kJ}$ & $\mathrm{ol}^{-1}$ & & & 0.91 \\
\hline & 100 & $A / \dot{\gamma}=1720.2 \dot{\gamma}$ & $5.62 ; E_{\mathrm{a}}=14.30 \mathrm{~kJ}$ & $\mathrm{ol}^{-1}$ & & & 0.93 \\
\hline & 200 & $A / \dot{\gamma}=1676.9 \dot{\gamma}-$ & $5.98 ; E_{\mathrm{a}}=13.94 \mathrm{~kJ}$ & $\mathrm{ol}^{-1}$ & & & 0.94 \\
\hline
\end{tabular}

${ }^{\mathrm{A}-\mathrm{E}}$ For the same column and for the same shear rate and parameter means without the same letter are significantly different $(P<0.05)$ according to the LSD multiple range test.

a-d For the same column and for the same temperature and parameter means without the same letter are significantly different $(P<0.05)$ according to the LSD multiple range test. Mean values $(n=3) \pm \mathrm{SD}$. 
Table 7

Parameters from Weltman and second-order structural kinetic models for vegetables and chicken puree at various temperatures and shear rates

\begin{tabular}{|c|c|c|c|c|c|c|c|}
\hline \multirow{2}{*}{$\begin{array}{l}\text { Temperature } \\
\left({ }^{\circ} \mathrm{C}\right)\end{array}$} & \multirow{2}{*}{$\begin{array}{l}\text { Shear } \\
\text { rate }\left(\mathrm{s}^{-1}\right)\end{array}$} & \multicolumn{3}{|l|}{ Weltman model } & \multicolumn{3}{|c|}{ Second-order structural kinetic model } \\
\hline & & $A(\mathrm{~Pa})$ & $-B(\mathrm{~Pa})$ & $R^{2}$ & $k \times 10^{2}\left(\mathrm{~s}^{-1}\right)$ & $\eta_{0} / \eta_{\mathrm{e}}$ & $R^{2}$ \\
\hline \multirow[t]{5}{*}{5} & 5 & $126.06 \pm 1.16^{\mathrm{A}}{ }_{\mathrm{d}}$ & $6.54 \pm 0.27_{c}^{\mathrm{A}}$ & 0.96 & $0.37 \pm 0.05_{\mathrm{c}}^{\mathrm{A}}$ & $1.72 \pm 0.02_{\mathrm{c}}^{\mathrm{A}}$ & 0.97 \\
\hline & 25 & $244.27 \pm 4.30^{\mathrm{A}}{ }_{c}^{\mathrm{a}}$ & $19.95 \pm 1.03^{\mathrm{A}}$ & 0.99 & $0.56 \pm 0.03^{\mathrm{B}, \mathrm{C}}$ & $2.62 \pm 0.06^{\mathrm{B}}$ & 0.99 \\
\hline & 50 & $249.45 \pm 3.10^{\mathrm{A}}$ & $19.17 \pm 0.11_{\mathrm{b}}^{\mathrm{A}}$ & 0.99 & $0.61 \pm 0.01_{b}^{C_{b}}$ & $2.65 \pm 0.01_{\mathrm{a}}^{\mathrm{B}}$ & 0.99 \\
\hline & 100 & $272.69 \pm 1.81_{b}^{\mathrm{A}}$ & $19.60 \pm 0.40_{\mathrm{b}}^{\mathrm{A}}$ & 0.99 & $0.69 \pm 0.08^{\mathrm{B}} \mathrm{a}, \mathrm{b}$ & $2.67 \pm 0.11_{\mathrm{a}}^{\mathrm{A}}$ & 0.99 \\
\hline & 200 & $351.88 \pm 1.11_{a}^{\mathrm{A}}$ & $25.77 \pm 0.22^{\mathrm{A}}$ & 1.00 & $0.80 \pm 0.04 \mathrm{C}_{\mathrm{a}}$ & $2.33 \pm 0.13^{\mathrm{C}_{\mathrm{b}}}$ & 0.99 \\
\hline \multirow[t]{5}{*}{20} & 5 & $110.03 \pm 2.02^{B}{ }_{c}^{a}$ & $5.65 \pm 0.33_{c}^{\mathrm{B}}$ & 0.92 & $0.28 \pm 0.05^{\mathrm{A}}{ }_{\mathrm{d}}$ & $1.69 \pm 0.06^{\mathrm{A}, \mathrm{B}}{ }_{\mathrm{d}}$ & 0.99 \\
\hline & 25 & $175.60 \pm 2.10^{\mathrm{B}}$ & $14.91 \pm 0.30_{\mathrm{b}}^{\mathrm{B}}$ & 0.98 & $0.53 \pm 0.01^{\mathrm{C}, \mathrm{D}}$ & $2.93 \pm 0.02^{\mathrm{A}} \mathrm{b}^{\mathrm{a}}$ & 0.99 \\
\hline & 50 & $189.28 \pm 3.20^{\mathrm{B}}$ & $15.16 \pm 1.01_{\mathrm{b}}^{\mathrm{B}}$ & 0.99 & $0.68 \pm 0.01_{b}^{\mathrm{B}}$ & $2.63 \pm 0.06_{c}^{\mathrm{B}}$ & 0.99 \\
\hline & 100 & $207.35 \pm 2.70^{\mathrm{B}}$ & $16.18 \pm 0.18^{\mathrm{B}}$ & 0.97 & $0.75 \pm 0.02^{\mathrm{B}}{ }_{\mathrm{b}}^{\mathrm{C}}$ & $2.73 \pm 0.05^{\mathrm{A}} \mathrm{b}, \mathrm{c}$ & 0.99 \\
\hline & 200 & $217.99 \pm 7.10^{\mathrm{B}}{ }_{\mathrm{a}}^{\mathrm{a}}$ & $18.38 \pm 0.29^{\mathrm{B}}$ & 0.97 & $0.98 \pm 0.02^{\mathrm{B}}$ & $3.27 \pm 0.12^{\mathrm{A}} \mathrm{a}$ & 0.99 \\
\hline \multirow[t]{5}{*}{35} & 5 & $73.75 \pm 1.21_{\mathrm{e}}^{\mathrm{C}}$ & $3.25 \pm 0.20^{C_{d}}$ & 0.95 & $0.33 \pm 0.07_{\mathrm{d}}^{\mathrm{A}}$ & $1.57 \pm 0.00^{\mathrm{B}}{ }_{\mathrm{d}}^{\mathrm{a}}$ & 0.97 \\
\hline & 25 & $117.94 \pm 5.03^{C_{d}}$ & $8.35 \pm 0.30^{C}{ }_{c}^{C}$ & 0.97 & $0.43 \pm 0.02_{c, d}^{D^{d}}$ & $2.27 \pm 0.04_{c}^{\mathrm{C}}$ & 0.99 \\
\hline & 50 & $134.23 \pm 0.23^{\mathrm{C}^{\mathrm{C}}}$ & $9.62 \pm 0.12^{\mathrm{C}}$ & 0.99 & $0.51 \pm 0.03^{\mathrm{D}}$ & $2.30 \pm 0.06^{C_{c}}$ & 0.99 \\
\hline & 100 & $153.58 \pm 2.11^{C_{b}^{c}}$ & $11.80 \pm 0.02^{C_{b}}$ & 0.98 & $0.61 \pm 0.05^{\mathrm{B}} \mathrm{a}, \mathrm{b}$ & $2.63 \pm 0.04^{\mathrm{A}}$ & 0.99 \\
\hline & 200 & $200.54 \pm 2.02^{C^{D}}$ & $13.79 \pm 1.10^{\mathrm{C}}{ }_{\mathrm{a}}^{\mathrm{D}}$ & 0.99 & $0.69 \pm 0.01_{a}^{c_{a}^{a, o}}$ & $2.45 \pm 0.03^{\mathrm{B}, \mathrm{C}_{\mathrm{b}}}$ & 0.97 \\
\hline \multirow[t]{5}{*}{50} & 5 & $45.99 \pm 2.09^{D_{c}}$ & $2.47 \pm 0.12^{\mathrm{C}, \mathrm{D}_{\mathrm{b}}}$ & 0.92 & $0.29 \pm 0.02^{\mathrm{A}_{\mathrm{e}}}$ & $1.64 \pm 0.01^{\mathrm{A}, \mathrm{B}_{\mathrm{c}}}$ & 0.98 \\
\hline & 25 & $75.56 \pm 1.20_{\mathrm{b}}$ & $6.47 \pm 0.21_{\mathrm{a}}^{\mathrm{D}}$ & 1.00 & $0.66 \pm 0.02_{\mathrm{d}}^{\mathrm{B}}$ & $2.92 \pm 0.05_{\mathrm{a}}^{\mathrm{A}}$ & 0.99 \\
\hline & 50 & $77.71 \pm 2.20_{\mathrm{b}}^{\mathrm{E}}$ & $6.38 \pm 0.02^{D_{a}^{\mathrm{a}}}$ & 0.99 & $0.86 \pm 0.01_{c}^{\mathrm{A}}$ & $2.93 \pm 0.05^{\mathrm{A}} \mathrm{a}$ & 0.99 \\
\hline & 100 & $82.78 \pm 0.20_{b}^{\mathrm{E}}$ & $6.39 \pm 0.30^{\mathrm{D}}{ }_{\mathrm{a}}^{\mathrm{a}}$ & 0.99 & $1.08 \pm 0.06_{\mathrm{b}}^{\mathrm{A}}$ & $2.87 \pm 0.01_{\mathrm{a}}^{\mathrm{A}}$ & 0.99 \\
\hline & 200 & $92.17 \pm 3.17_{\mathrm{a}}^{\mathrm{E}}$ & $6.82 \pm 0.11_{a}^{\mathrm{E}}$ & 0.98 & $1.76 \pm 0.04_{\mathrm{a}}^{\mathrm{A}}$ & $2.72 \pm 0.02^{\mathrm{B}}{ }_{\mathrm{b}}^{\mathrm{a}}$ & 0.98 \\
\hline \multirow[t]{6}{*}{65} & 5 & $41.83 \pm 1.11^{\mathrm{D}} \mathrm{e}^{\mathrm{a}}$ & $2.33 \pm 0.10^{D_{d}^{a}}$ & 0.99 & Not applicable & & \\
\hline & 25 & $63.50 \pm 1.20^{\mathrm{E}}{ }_{\mathrm{d}}^{\mathrm{C}}$ & $4.34 \pm 0.11_{c}^{\mathrm{E}}$ & 0.97 & $1.10 \pm 0.05^{\mathrm{A}}$ & $2.16 \pm 0.10^{\mathrm{C}}$ & 1.00 \\
\hline & 50 & $88.51 \pm 1.30^{\mathrm{D}}{ }_{c}$ & $6.84 \pm 0.12^{\mathrm{D}}{ }_{\mathrm{b}}^{\mathrm{c}}$ & 0.99 & Not applicable & & \\
\hline & 100 & $97.64 \pm 0.34^{\mathrm{D}}$ & $7.14 \pm 0.04_{b}^{D_{b}}$ & 0.99 & Not applicable & & \\
\hline & 200 & $120.37 \pm 2.20_{\mathrm{a}}^{\mathrm{D}}$ & $9.91 \pm 0.99^{\mathrm{D}}$ & 0.98 & Not applicable & & \\
\hline & & \multicolumn{6}{|c|}{ Power law and logarithmic models } \\
\hline \multicolumn{2}{|l|}{5} & \multicolumn{2}{|c|}{$A=55.54 \ln (\dot{\gamma})+41.758$} & 0.94 & \multicolumn{2}{|c|}{$k=2.74 \times 10^{-3} \dot{\gamma}^{0.204}$} & 0.99 \\
\hline \multicolumn{2}{|l|}{20} & \multicolumn{2}{|c|}{$A=29.42 \ln (\dot{\gamma})+70.359$} & 0.97 & $k=1.72 \times 10^{-3} \dot{\gamma}$ & & 0.98 \\
\hline \multirow[t]{2}{*}{35} & & \multicolumn{2}{|l|}{$A=49.01 \dot{\gamma}^{0.260}$} & 0.99 & \multicolumn{2}{|c|}{$k=232 \times 10^{-3} \cdot 0.205$} & 0.99 \\
\hline & & \multicolumn{2}{|c|}{$B=2.82 \ln (\dot{\gamma})-1.151$} & 1.00 & & & \\
\hline \multicolumn{2}{|l|}{50} & \multicolumn{2}{|c|}{$A=11.91 \ln (\dot{\gamma})+30.441$} & 0.94 & $k=1.38 \times 10^{-3} \dot{\gamma}$ & & 0.99 \\
\hline \multicolumn{2}{|l|}{65} & \multicolumn{2}{|l|}{$A=26.20 \dot{\gamma}^{0.290}$} & 0.99 & Not applicable & & \\
\hline \multirow{5}{*}{$\begin{array}{l}\text { Arrehnius } \\
\text { model }\end{array}$} & 5 & \multicolumn{5}{|c|}{$A / \dot{\gamma}=1925.4 \dot{\gamma}-3.61 ; E_{\mathrm{a}}=16.01 \mathrm{~kJ} \mathrm{~mol}^{-1}$} & 0.95 \\
\hline & 25 & \multicolumn{5}{|c|}{$A / \dot{\gamma}=2220.7 \dot{\gamma}-5.68 ; E_{\mathrm{a}}=18.46 \mathrm{~kJ} \mathrm{~mol}^{-1}$} & 0.99 \\
\hline & 50 & $A / \dot{\gamma}=1870.8 \dot{\gamma}$ & $5.11 ; E_{\mathrm{a}}=15.55 \mathrm{k}$ & $\mathrm{mol}^{-1}$ & & & 0.92 \\
\hline & 100 & $A / \dot{\gamma}=1875.3 \dot{\gamma}-$ & $5.72 ; E_{\mathrm{a}}=15.59 \mathrm{k}$ & $\mathrm{mol}^{-1}$ & & & 0.90 \\
\hline & 200 & $A / \dot{\gamma}=1903.7 \dot{\gamma}$ & $6.33 ; E_{\mathrm{a}}=15.83 \mathrm{k}$ & $\operatorname{mol}^{-1}$ & & & 0.84 \\
\hline
\end{tabular}

${ }^{\mathrm{A}-\mathrm{E}}$ For the same column and for the same shear rate and parameter means without the same letter are significantly different $(P<0.05)$ according to the LSD multiple range test.

${ }_{a-d}$ For the same column and for the same temperature and parameter means without the same letter are significantly different $(P<0.05)$ according to the LSD multiple range test. Mean values $(n=3) \pm \mathrm{SD}$. 
(a)

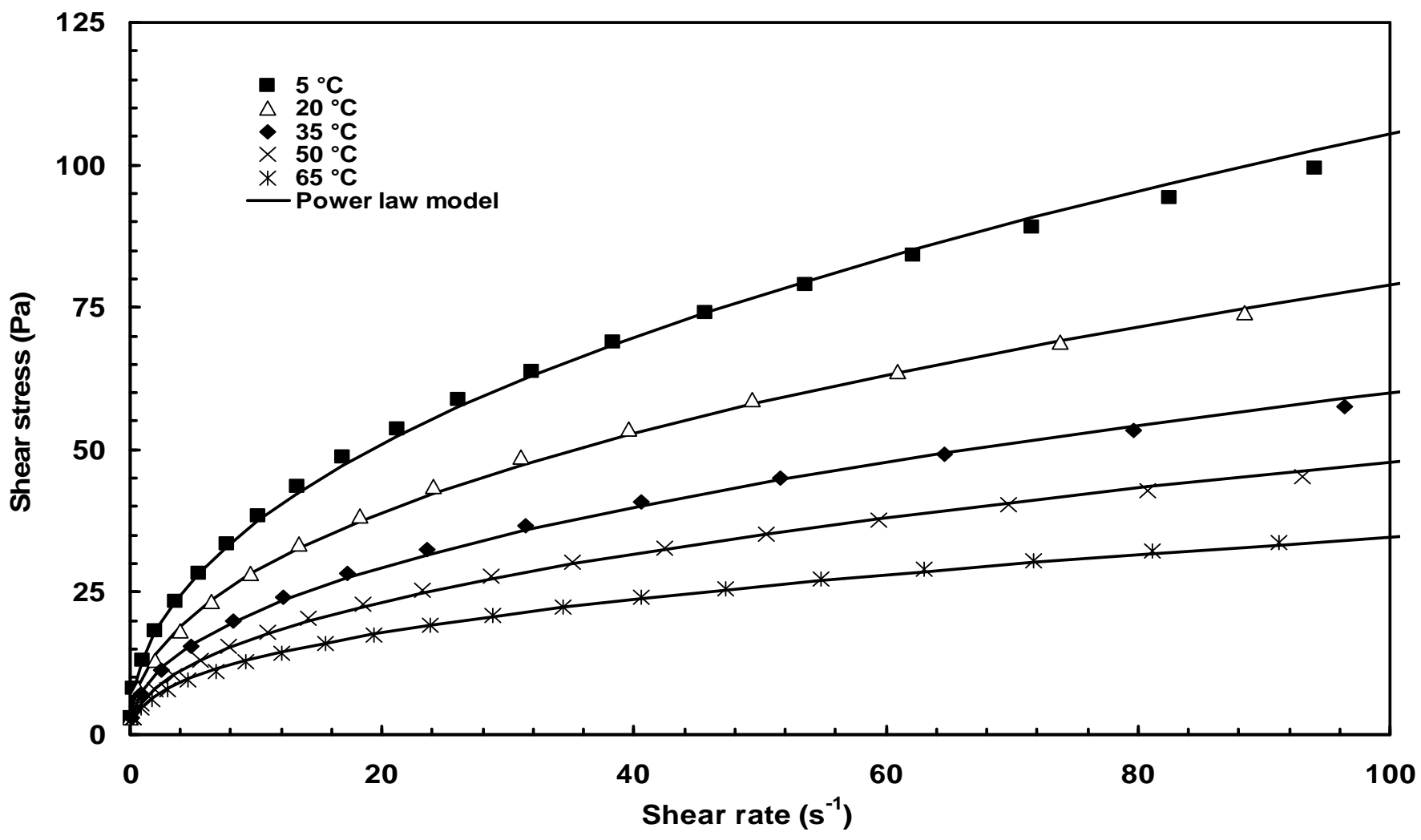

(b)

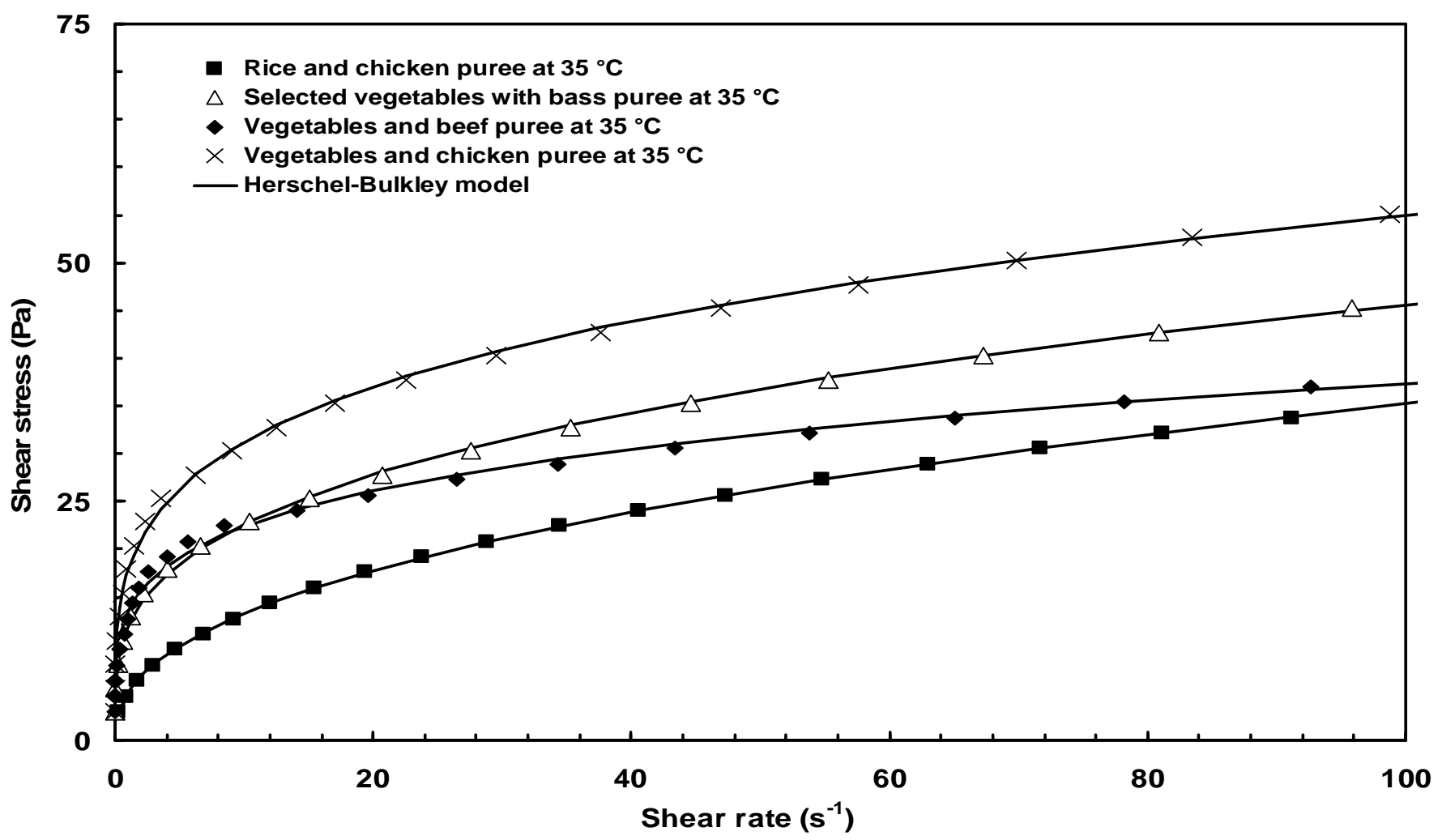

Fig. 1. Flow curves with a controlled shear stress (CSS mode) of vegetable-based infant purees measured by increasing shear rate (forward measurements). (a) Rice and chicken puree at different temperatures fitted to the power law model; (b) Vegetable-based infant purees at $35^{\circ} \mathrm{C}$ fitted to the Herschel-Bulkley model. 


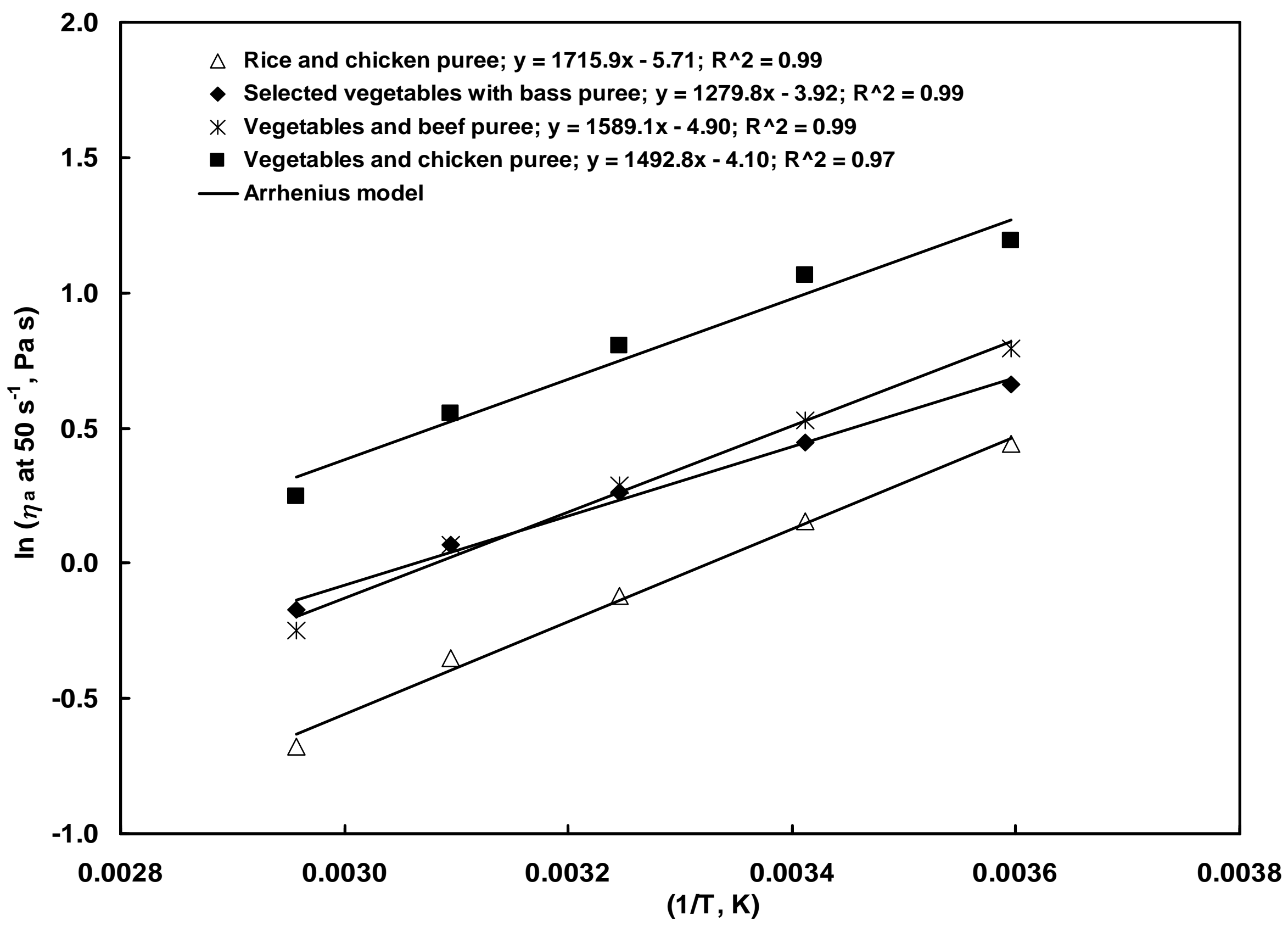

Fig. 2. Plots of apparent viscosity (CSS mode) vs. temperature for vegetable-based infant purees. 
(a)

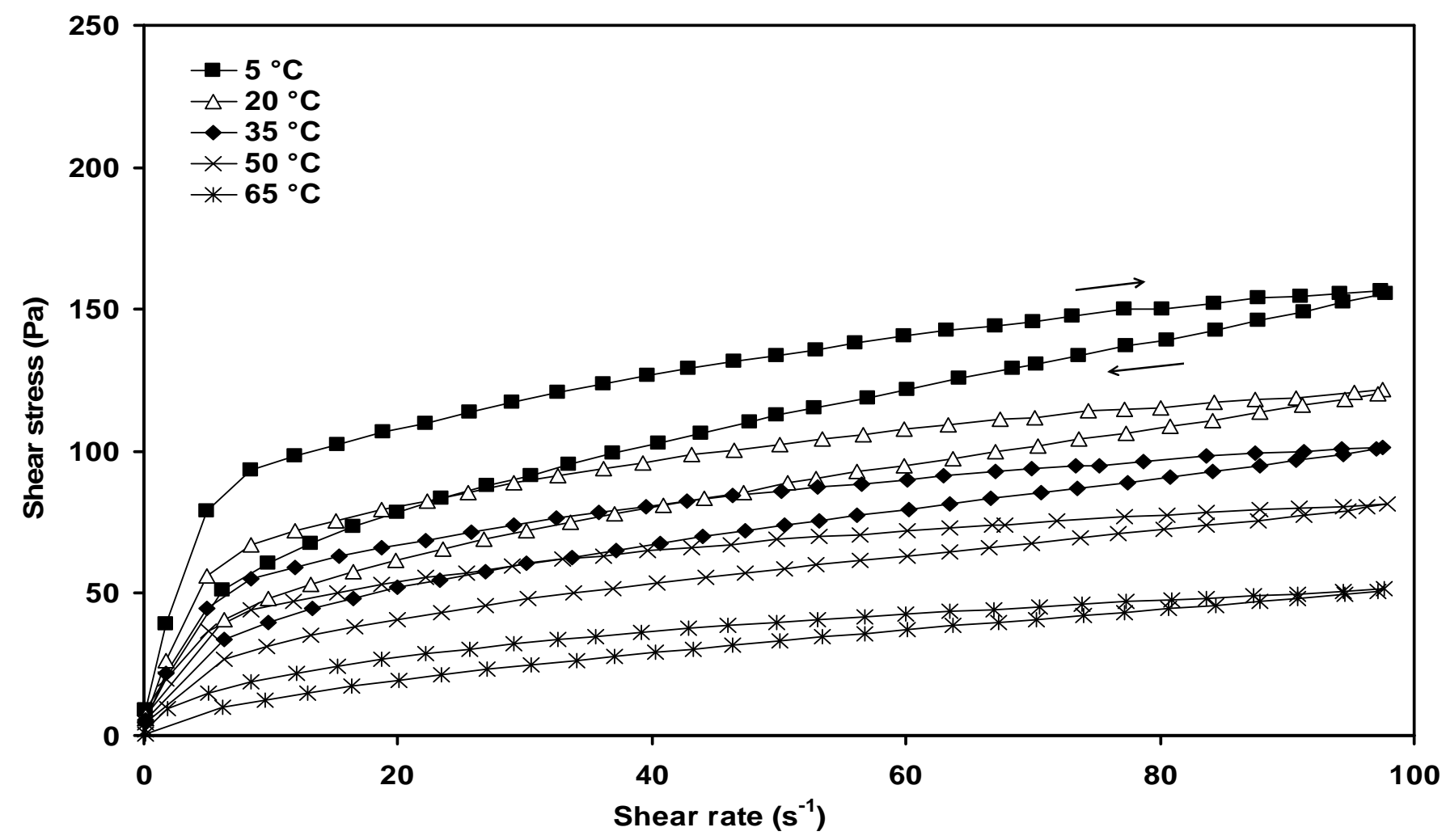

(b)

Vegetables and chicken puree

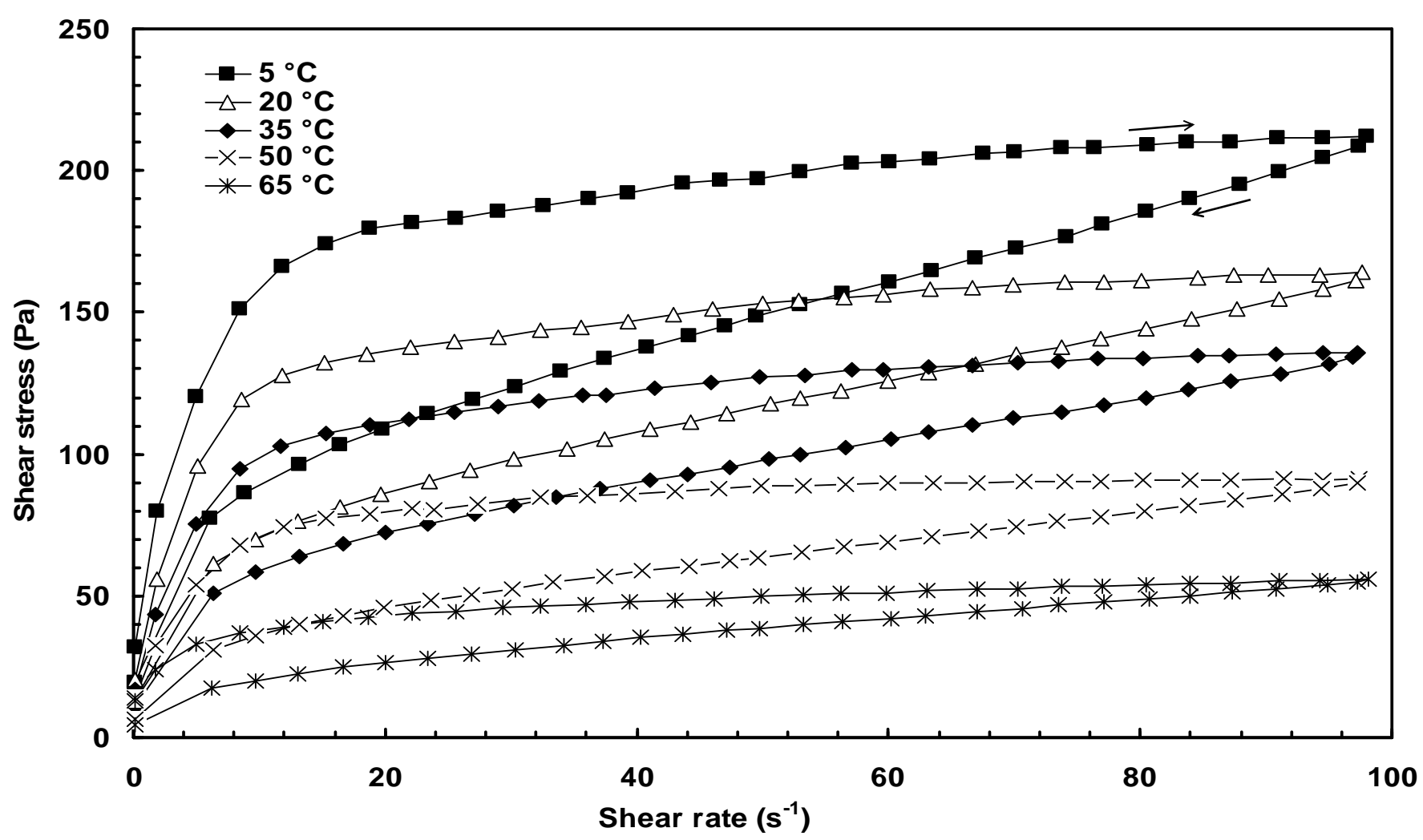

Fig. 3. Flow curves with a controlled shear rate (CSR mode) measured by increasing (forward measurements) and decreasing shear rate (backward measurements) at temperatures of 5, 20, 35, 50 and $65^{\circ}$ C. (a) Selected vegetables with bass puree; (b) Vegetables and chicken puree. 
(a)

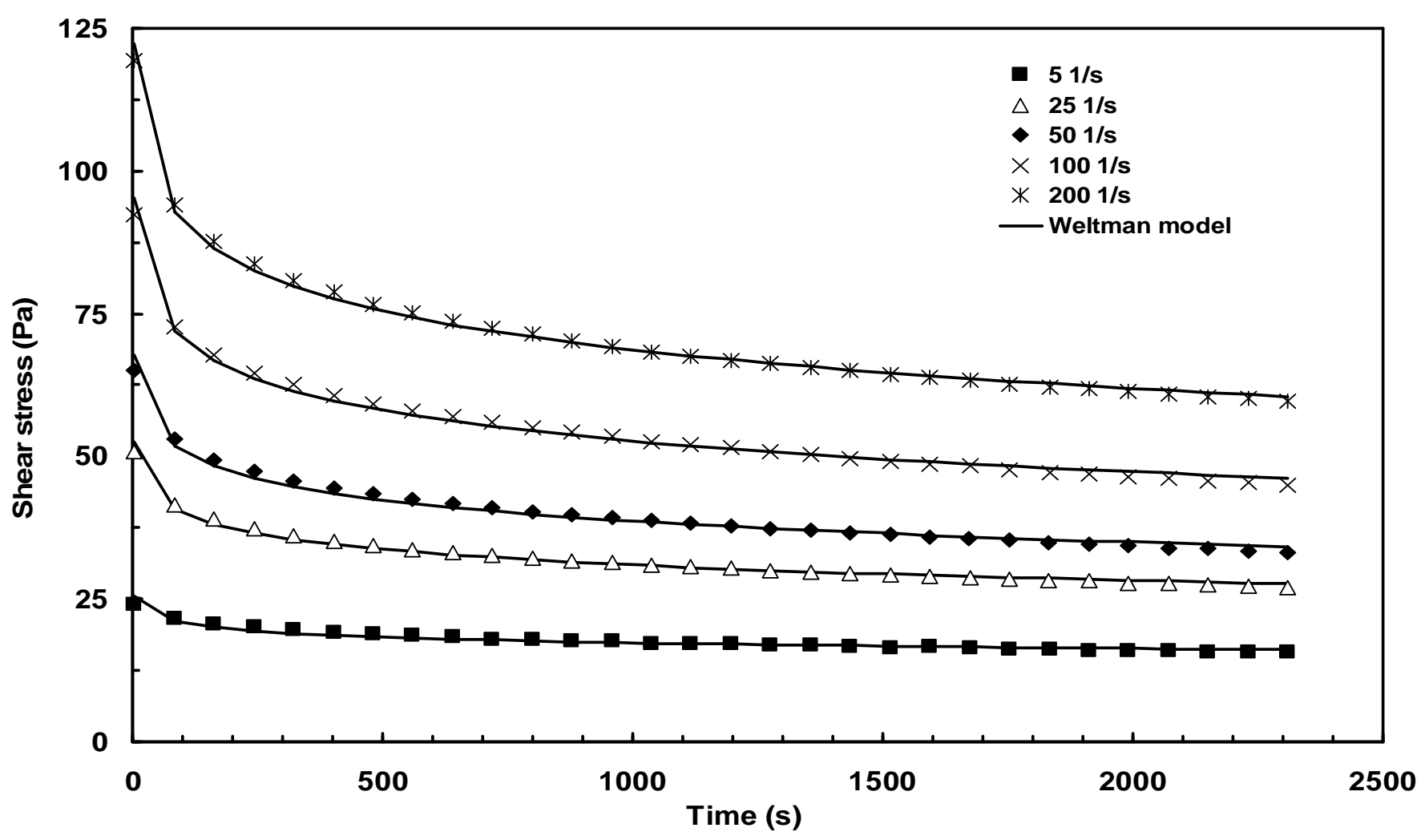

(b)

\section{Vegetables and beef puree sheared at $100 \mathrm{~s}^{-1}$}

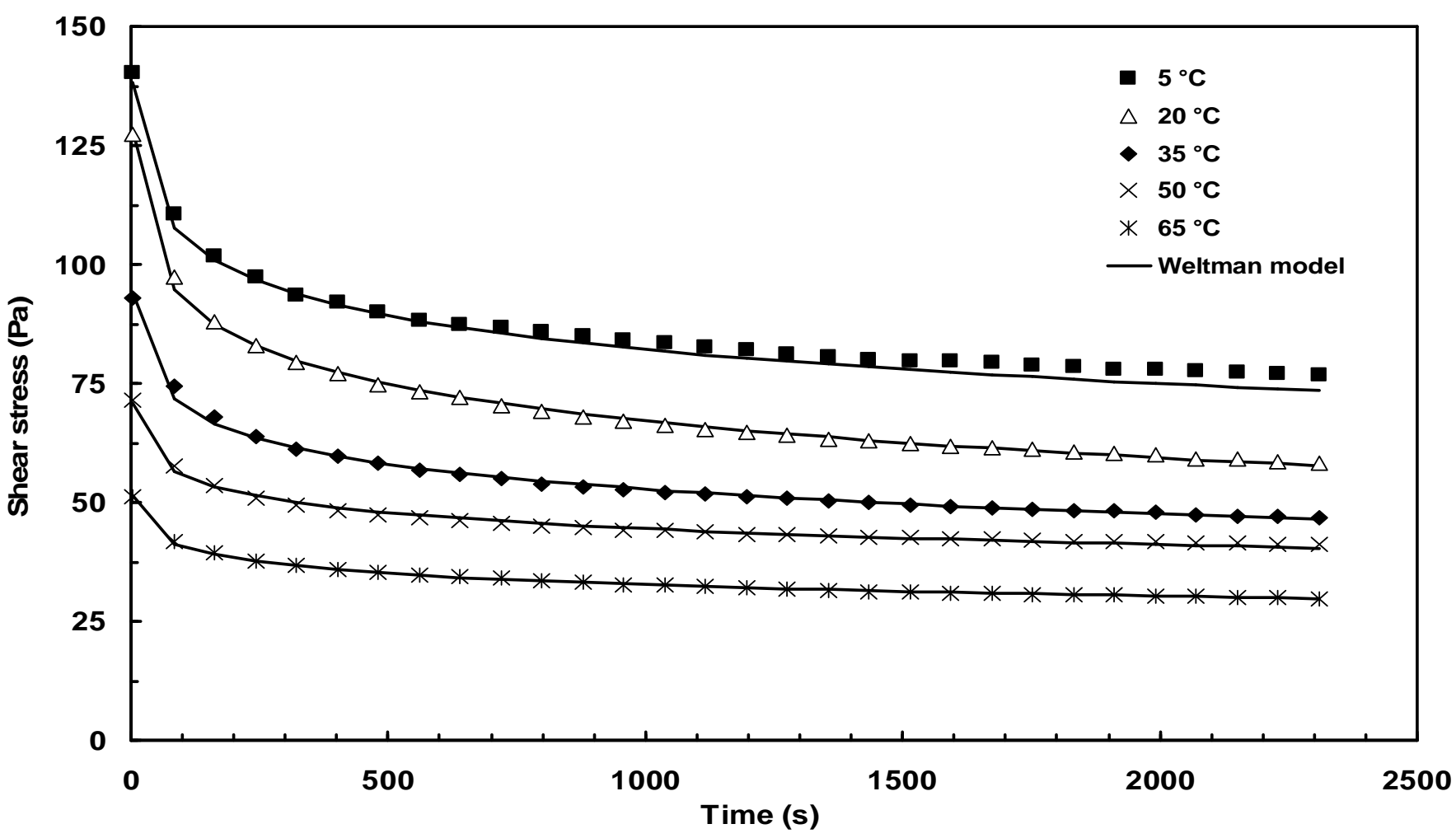

Fig. 4. Experimental and predicted shear stress values as a function of shearing time. (a) Rice and chicken puree at $35^{\circ} \mathrm{C}$ at different shear rates $\left(5-200 \mathrm{~s} \mathrm{~s}^{-1}\right)$. (b) Vegetables and beef puree sheared at $100 \mathrm{~s}^{-1}$ at different temperatures $\left(5-65^{\circ} \mathrm{C}\right)$. 
(a)

Selected vegetables with bass puree sheared at $100 \mathrm{~s}^{-1}$

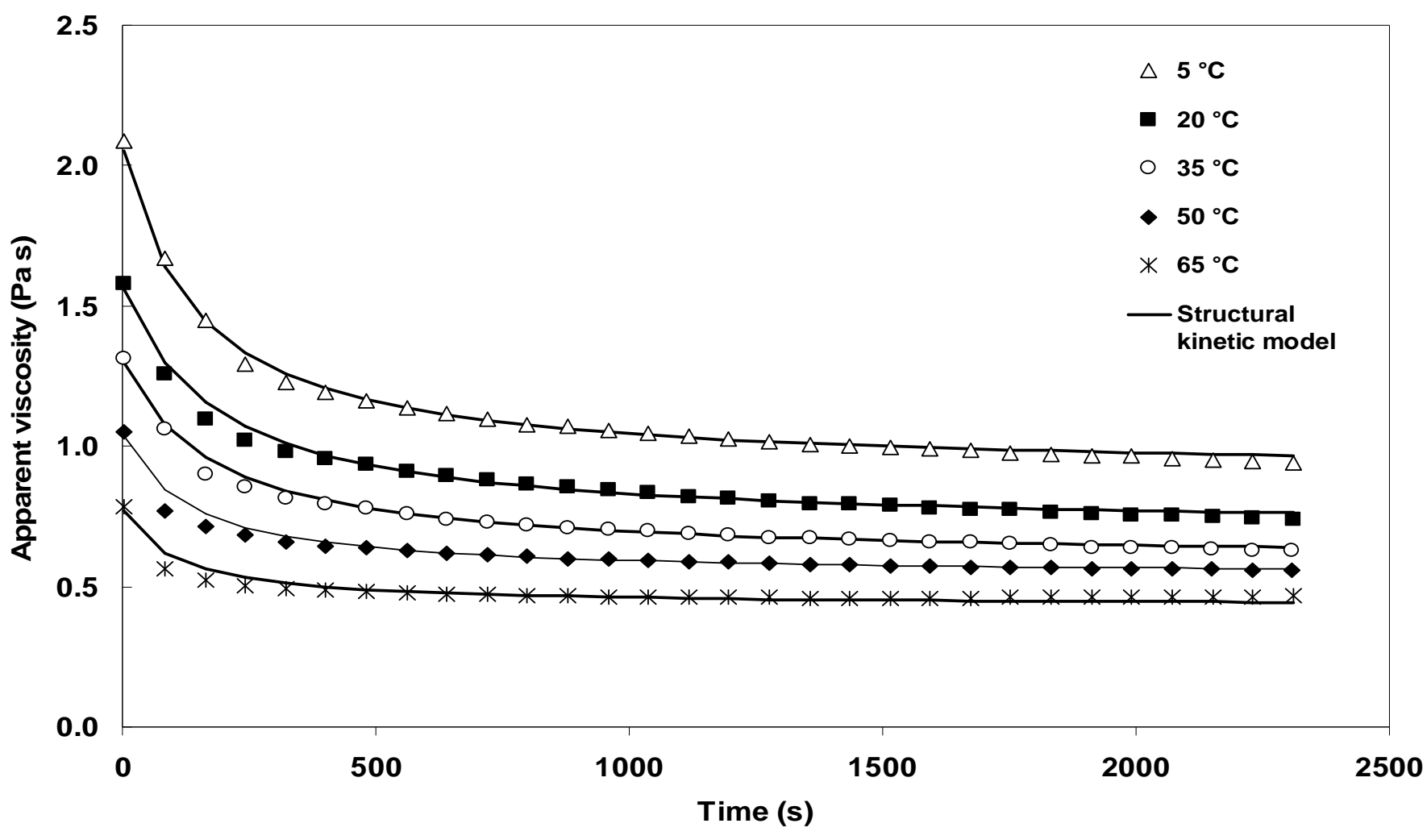

(b) Vegetables and chicken puree sheared at $25 \mathrm{~s}^{-1}$

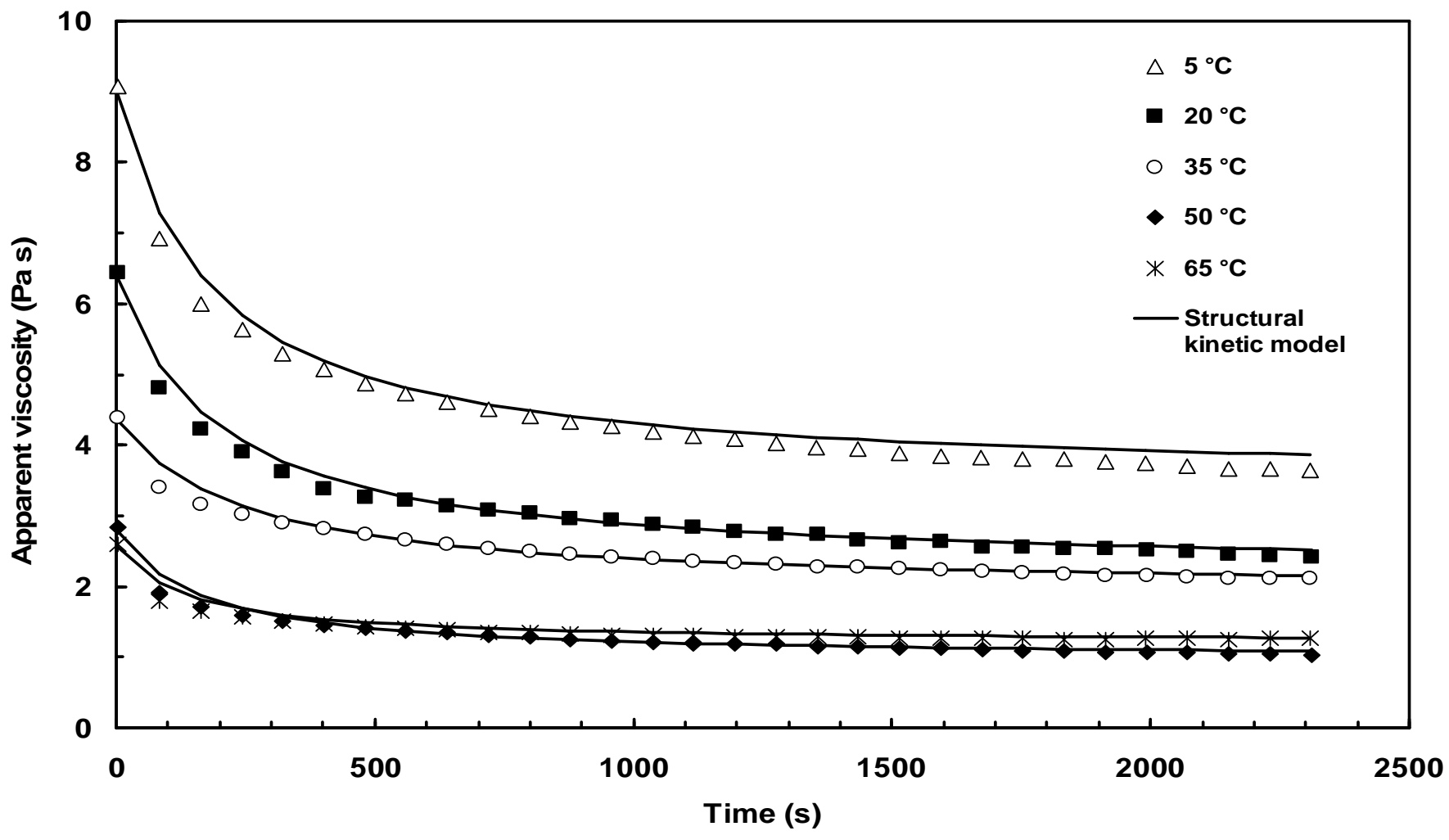

Fig. 5. Experimental and predicted apparent viscosity values as a function of shearing time at different temperatures $\left(5-65^{\circ}\right.$ C). (a) Selected vegetables with bass puree at a constant shear rate of $100 \mathrm{~s}^{-1}$; (b) Vegetables and chicken puree at a constant shear rate of $25 \mathrm{~s}^{-1}$. 
(a)

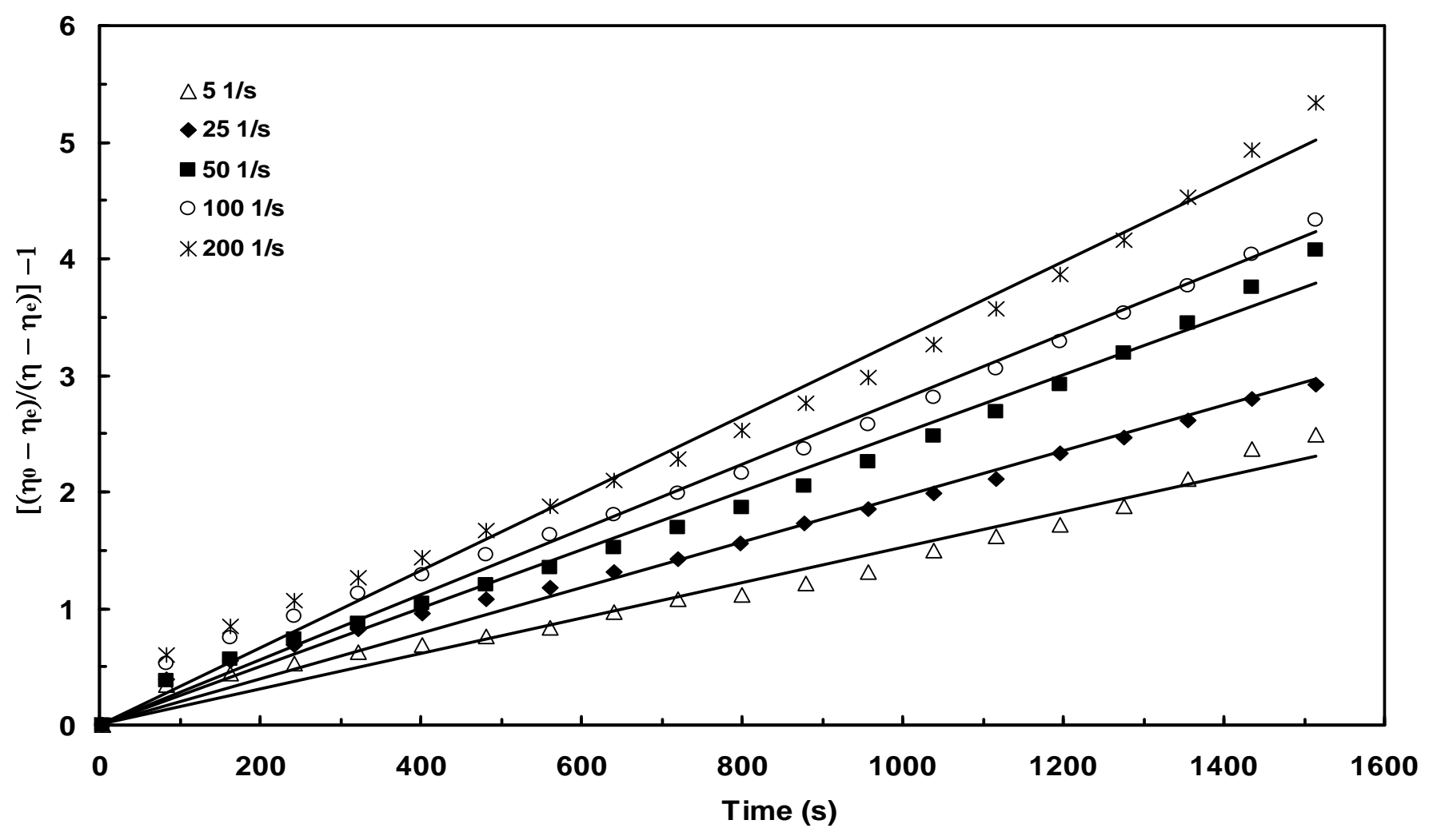

(b)

Vegetables and chicken puree sheared at $100 \mathrm{~s}^{-1}$

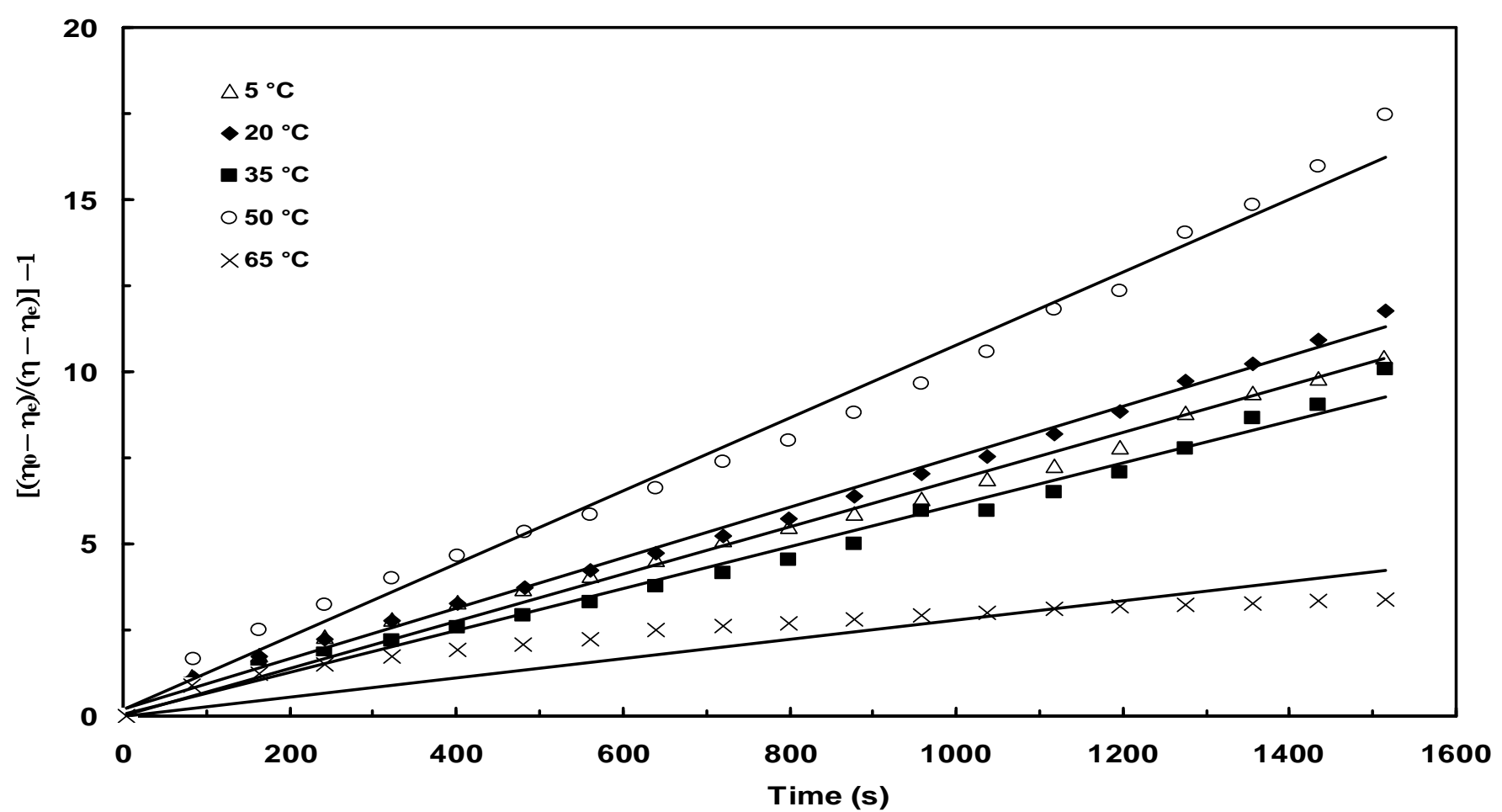

Fig. 6. Testing of the second-order structural kinetic model, Eq. (6), for some vegetable-based infant purees. (a) Rice and chicken puree at $50^{\circ} \mathrm{C}$ and different shear rates; (b) Vegetables and chicken puree at a constant shear rate of $100 \mathrm{~s}^{-1}$ and different temperatures. 


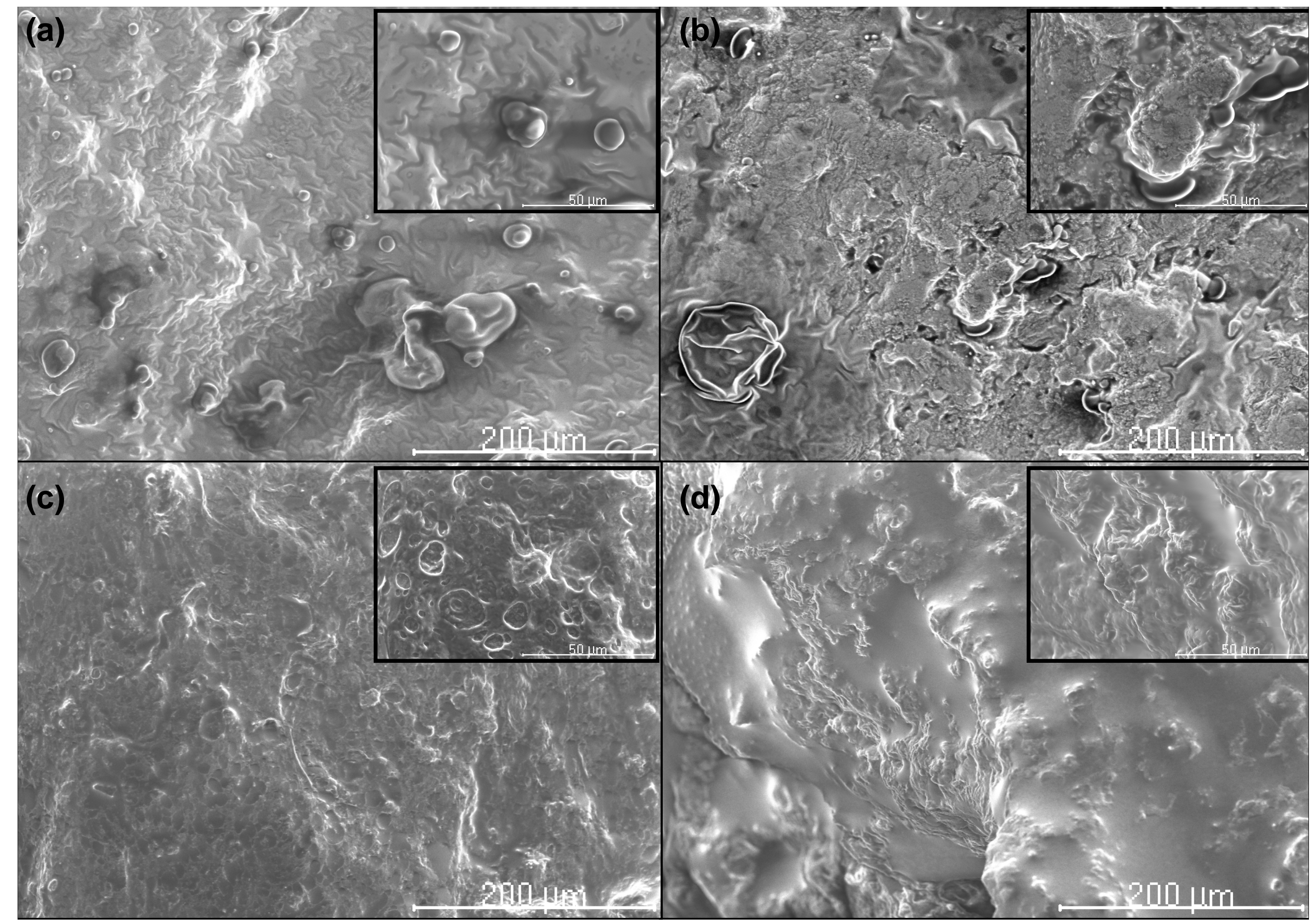

Fig. 7. Micrographs of vegetable-based infant purees. (a) Rice and chicken puree; (b) Selected vegetables with bass puree; (c) Vegetables and beef puree; (d) Vegetables and chicken puree. 